\title{
Effects of Nonaqueous Phase Liquids Pollution on the Permeability and Microstructure of In-Filed and Laboratory Soaked Contaminated Clay Soils
}

\author{
Yanbin Gao $\mathbb{D}^{1,2}$ and Jiadan Liu $\mathbb{D}^{1,2}$ \\ ${ }^{1}$ Department of Geotechnical Engineering College of Civil Engineering, Tongji University, Shanghai 200092, China \\ ${ }^{2}$ Key Laboratory of Geotechnical and Underground Engineering of the Ministry of Education, Tongji University, \\ Shanghai 200092, China
}

Correspondence should be addressed to Jiadan Liu; 1510264@tongji.edu.cn

Received 19 January 2022; Revised 31 January 2022; Accepted 4 February 2022; Published 22 February 2022

Academic Editor: Zhongguang Sun

Copyright (C) 2022 Yanbin Gao and Jiadan Liu. This is an open access article distributed under the Creative Commons Attribution License, which permits unrestricted use, distribution, and reproduction in any medium, provided the original work is properly cited.

\begin{abstract}
The fact that the permeability and microstructure properties of clay will be changed by NAPL (Nonaqueous Phase Liquids) pollution draws high attention in the study of the interaction between NAPL and contaminated soil. Through in-field contaminated clay soils from vinyl chloride and 1,1,2-trichloroethane-contaminated site in Shanghai, the variation of the content of vinyl chloride and 1, 1,2-trichloroethane pollutants in clay with depth was obtained. The change of plasticity, permeability, and microstructure properties of the clay samples contaminated by vinyl chloride and 1, 1, 2-trichloroethane were investigated in detail. The measured test results were compared with the uncontaminated clay and indoor soaked contaminated clay samples by TCE (Trichloroethylene). The test results showed that the microstructure characteristics of clay were changed under the influence of the content of TCE, vinyl chloride, and 1, 1,2-trichloroethane. The total porosity, accumulative pore volume, and the content of the macroporosity percentage of clay soils showed an increasing trend. The flocculation structure of contaminated clay samples was observed, but there were no overhead pores and connected cracks. Volatile organic pollutants were detected in both field and indoor contaminated clay samples. The plastic limit and liquid limit of each layer of contaminated samples decreased slightly, the plastic index did not change significantly, and the pore ratio and permeability coefficient increased gently. At the same time, the clay shrinkage was aggravated by TCE pollution, and cracks appeared on the surface of soil samples. However, no connected cracks were formed. Test results indicated that the self-developed improved permeability test device can be used to test the permeability coefficient of clay samples with shrinkage and to crack by NAPL pollution. The permeability coefficient showed an increasing trend, though the increase was not at the level of magnitude.
\end{abstract}

\section{Introduction}

NAPLs (Nonaqueous Phase Liquids) are one of the main factors that cause pollution incidents. Due to the high toxicity of most NAPLs, the presence of a small amount of NAPL in soil and water could have a great impact on human safety and the ecological environment [1]. Among them, DNAPL (Dense Nonaqueous Phase Liquids) can migrate downwards to deeper soil, causing the pollution of deep water and soil. The migration process involves complex physicochemical interactions between pore-water solution-clay minerals and organic matter-NAPLs, and the migration characteristics of NAPLs in saturated clay soils and their interaction with clay are complex.

The permeability of soil is one of the most important factors affecting pollutant migration. For saturated clay soil, its complex and diverse microstructure lead to the complexity of permeability characteristics. The complex physicochemical interactions between pollutants and cohesive soils may alter their microstructural properties and permeability properties, thereby ultimately affecting the transport properties of pollutants [2]. As early as the 1970s 
and 1980s, it was noticed that some pure organic liquids could change the microstructure and permeability characteristics of cohesive soils [3-8]. This has drawn attention to the study of the interaction between organic pollutants and cohesive soils. Since then, a large number of researchers have focused on the related environmental, geotechnical engineering problems caused by petroleum engineering and petroleum refining products (gasoline, kerosene, and diesel, etc.). For example, extensive work has been done on the interaction and permeability characteristics of gasoline, kerosene, and diesel, and other organic pollutants with clayey soils [9-17]. Until now, these objects are still one of the important contents of environmental geotechnical engineering research. Some domestic scholars have also carried out related research work $[18,19]$. The overall conclusion is that the change in permeability coefficient is related to the dielectric constant of organic solutions. This is because the dielectric constant of the organic solution is much lower than that of the pore water. When the organic solution interacts with the clay sample, the thickness of the electric double layer of the clay sample would be decreased, and the clay would flocculate or even show shrinkage due to water loss and cracking on the macroscopic scale.

In the studies mentioned above, most of the permeability coefficients were measured using traditional permeability test devices. For example, a rigid wall permeability test device is used to measure the permeability coefficient by injecting a certain organic solution or a mixture of several solutions into the uncontaminated soil samples, and then the change of the permeability coefficient of the clay sample during the injection process was observed. First of all, this injection test method has a prominent boundary effect problem, that is, the lateral shrinkage of the soil sample leads to leakage of the sidewall, resulting in an excessively large permeability coefficient [20-24]. Test results have shown that with the same test material, the permeability coefficient obtained in the rigid wall test would be several hundred times larger, while the change in the flexible wall test is much smaller [4, 25]. However, even the flexible wall test cannot truly reflect the state of the field contaminated soils (such as stress state, pollutant concentration, pollutant composition, etc.), so the rationality of these test results was still in doubt. In addition, due to the limitation of test equipment, the indoor permeability test was generally carried out for a limited time, at most a few months, which was quite different from the pollution period of more than ten years or even decades in the field. This is another major difference between indoor permeability tests and field tests. At present, there are very few research data on the permeability coefficient of the contaminated clay samples under the long-term interaction of NAPL.

Therefore, this paper studies the relationship between NAPL pollutants and saturated clay of the changes in microstructural properties and permeability properties under long-term interaction tests. These tests were based on different pollutant types (field polluted soil and soaking contaminated pollution), with different initial structural properties samples (Shanghai layer (2)-(5) clay). In addition, a typical contaminated soil sample was taken from an organically polluted site in Shanghai, and a series of experimental studies were carried out on the prepared contaminated clay samples. At the same time, the contaminated soil samples soaked in trichloroethylene were prepared by the indoor long-term immersion method. In order to further understand and study the changes in the permeability characteristics of NAPL-contaminated saturated clay soils and indoor soaked contaminated clay samples under longterm interactions with pollutants, an improved rigid-wall permeability test was carried out in this paper, and the permeability coefficient of contamination samples after shrinkage and cracking was obtained. The purpose of this paper was to investigate the changes of clay microstructure and permeability characteristics of NAPL and clay samples under the long-term interaction and interaction mechanisms.

\section{Materials and Methods}

2.1. The Field Contaminated Soil Samples of Vinyl Chloride and 1, 1,2-Trichloroethane. The field contaminated soil samples used in the test were taken from a hydrogen chloride contaminated site in Shanghai. The shallow layer of the site is mainly saturated clay soil. The distribution of soil layers and the composition and content of contaminants are obtained by sampling boreholes at typical locations. The soil layer distribution and indicators are shown in Figure 1. Among them, layer (2) is gray-yellow silty clay, layer (3) is gray silty clay, layer (4) is gray silty clay, and layer (5) is gray clay. The typical photos of the field contaminated soils of the Shanghai layer (4) are shown in Figure 2. The mineral components of the clay samples used in the experiment are mainly illitebased minerals, and the nonclay minerals are mainly quartz and also contain Albite $\left(\mathrm{Na}_{2} \mathrm{O} \bullet \mathrm{Al}_{2} \mathrm{O}_{3} \bullet 6 \mathrm{SiO}_{2}\right)$, mica, and some carbonate minerals dolomite $\left(\mathrm{CaMg}\left(\mathrm{CO}_{3}\right)_{2}\right)$, etc. $[26,27]$.

The results of the detection of the main components of volatile organic compounds in the site showed that the main pollutants in the site were vinyl chloride $\left(\mathrm{C}_{2} \mathrm{H}_{3} \mathrm{Cl}\right)$ and 1,1 , 2-trichloroethane $\left(\mathrm{CH}_{2} \mathrm{ClCHCl}_{2}\right)$. The characteristics of these pollutions are shown in Table 1, and the cation exchange capacity of each layer of saturated clay before and after the on-site vinyl chloride pollution is shown in Table 2. The distribution law of the detected value of the content of vinyl chloride pollutants in each soil layer with the depth of the soil layer is shown in Figure 1. The soil layer above the buried depth of $22 \mathrm{~m}$ has been polluted to varying degrees. The detection values of clay pollutants in layers (3) and (4) are relatively high.

It can be seen from the test results in Table 2 that the cation exchange content of the field contaminated clays detected in the test is generally greater than that of the uncontaminated clays. A larger cation exchange content will lead to a smaller thickness of the electric double layer, while a decrease in the thickness of the electric double layer of the diffusion layer will reduce the bound water content, thereby increasing the effective porosity and ultimately leading to an increase in the permeability coefficient. 


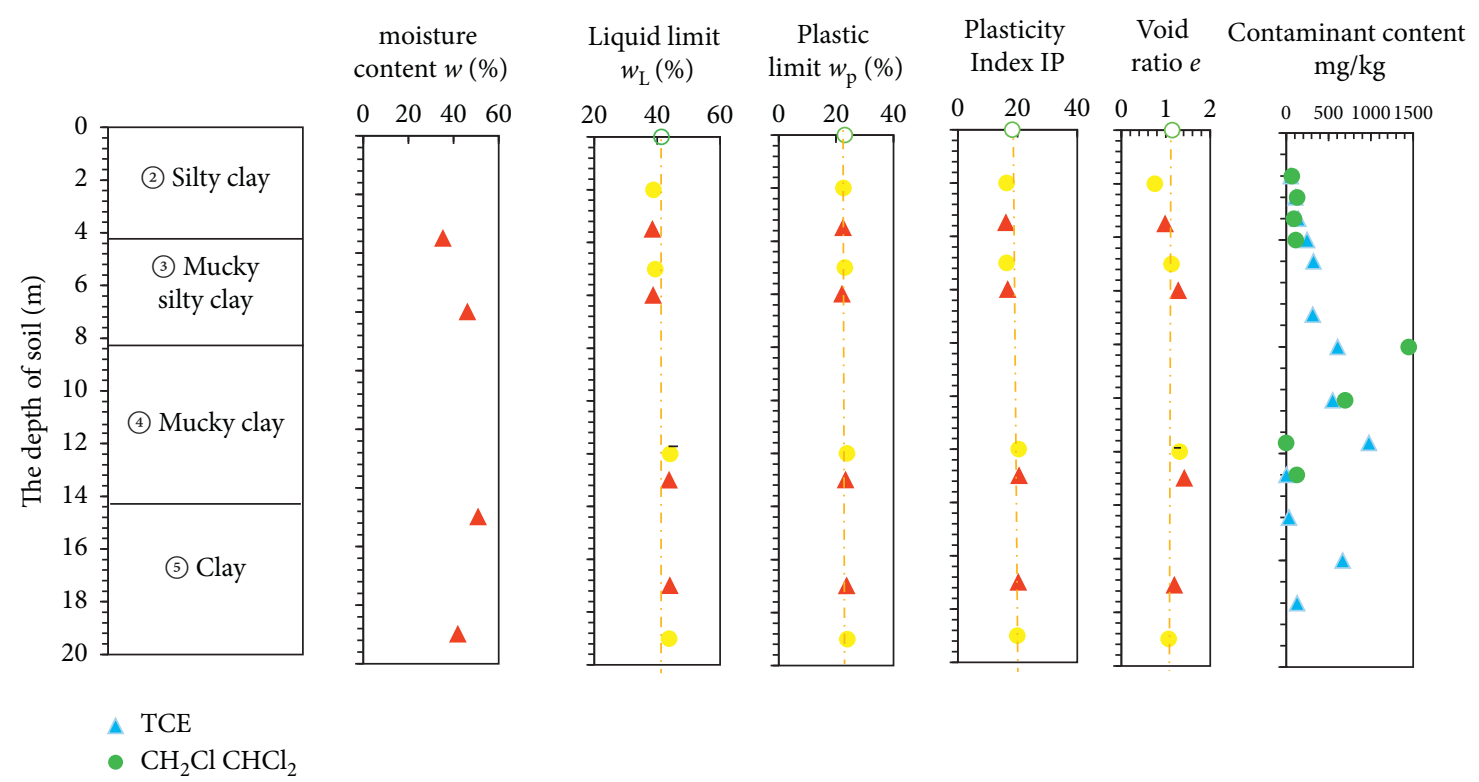

Figure 1: Soil layer distribution and basic physical and mechanical indexes.

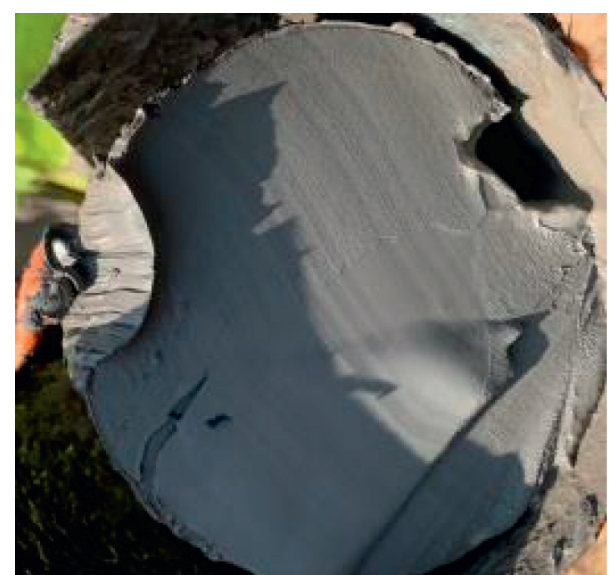

Figure 2: Typical photos of the field contaminated soils (layer (4)).

TABLe 1: The properties of organic pollutants $\left(20^{\circ} \mathrm{C}\right)$.

\begin{tabular}{lccccc}
\hline $\begin{array}{l}\text { Organic } \\
\text { pollutants }\end{array}$ & $\begin{array}{c}\text { Dielectric constant } \\
(-)\end{array}$ & $\begin{array}{c}\text { Water solubility }(\mathrm{mg} / \\
\mathrm{L})\end{array}$ & $\begin{array}{c}\text { Density }(\mathrm{g} / \\
\left.\mathrm{cm}^{3}\right)\end{array}$ & $\begin{array}{c}\text { Viscosity } \\
(\mathrm{cP})\end{array}$ & $\begin{array}{c}\text { Octanol-water partition coefficient (log } \\
\text { kow) }\end{array}$ \\
\hline Distilled water & 78.52 & - & 1 & 1.002 & - \\
TCE & 3.4 & 1368 & 1.464 & 0.58 & 2.42 \\
Vinyl chloride & 1.01 & 2920 & 1.334 & 0.18 & 1.38 \\
$\mathrm{CH}_{2} \mathrm{CLCHCL}$ & 7.52 & 4360 & 1.435 & 1.69 & 2.17 \\
\hline
\end{tabular}

TABLE 2: The cation exchange capacity of uncontaminated saturated clay and contaminated with TCE saturated clay.

\begin{tabular}{lcr}
\hline \multirow{2}{*}{ Soil layer } & \multicolumn{2}{c}{ cation exchange capacity $(\mathrm{cmol} / \mathrm{kg})$} \\
& The field contaminated soil samples & Uncontaminated soil samples \\
\hline Layer (2) & 14.0 & 13.3 \\
Layer (3) & 12.1 & 11.3 \\
Layer (4) & 17.9 & 12.6 \\
Layer (5) & 12.9 & 10.0 \\
\hline
\end{tabular}


The cation exchange content of the field contaminated clays samples obtained from the test results is greater than the permeability coefficient of the uncontaminated clay samples, which means that the permeability characteristics of the contaminated clay samples are likely to change, and the permeability coefficient will become larger. This also reflects that the internal microstructural properties of the field contaminated clay samples are likely to change. Therefore, the detection of cation exchange content will help analyze the changes in the microstructure and permeability characteristics of the field contaminated clays samples.

\subsection{Long-Term Indoor Soaked Contaminated Soil Samples of} TCE. Indoor long-term soaking experiments by TCE were carried out on the clays of Shanghai layers (2)-(5). A ring knife with a diameter of $4 \mathrm{~cm}$ and an area of $30 \mathrm{~cm}^{2}$ was used to prepare the original saturated clay sample and the basic physical and mechanical indexes are shown in Table 3. Then the ring knife sample was first wrapped with a filter screen and then placed in a glass jar filled with trichloroethylene, which was shown in Figure 3. In order to prevent the photolysis of trichloroethylene, the immersed airtight glass jar was covered with an opaque black sealed bag, placed in a sealed carton, and then placed in a fume hood as a whole.

The contaminated clay samples were photographed at different soaking times. Figures 4 and 5 show the apparent characteristics of the clay samples in the Shanghai (2)-(5) layers after trichloroethylene immersion for 212 days (about 7 months), 379 days (about 13 months).

As can be seen from Figures 4 and 5, the surface color of the clay under trichloroethylene soaked and contamination showed "blackening" phenomenon, the lateral shrinkage of the fourth layer was obvious, while some cracks were observed on the surface of the third layer, and the height of the soil samples did not change significantly. With the passage of soaking time, the shrinkage of the clay body was intensified, and the number of surface cracks was increased, but no penetration and connection was observed.

Tables 4 and 5 summarize the number of cracks $N$, the diameter shrinkage rate $L$, and the gap between the clay sample and the ring knife changes in $D(\mathrm{~cm})$ and area ratio $S$ after the interaction time at $t=212$ days and $t=379$ days.

From the summary statistics in Table 4 , it can be seen that the layer (5) of Shanghai clay samples experienced the most obvious shrinkage, with diameter shrinkage of $5.85 \%$ and area shrinkage of $11 \%$, but no cracks were observed on the surface of the clay samples. The layer (2) of Shanghai clay samples experienced the second-largest shrinkage, with a diameter shrinkage rate of $3.87 \%$ and an area shrinkage rate of $8 \%$. A relatively obvious crack appeared on the surface of the clay sample, and the apparent color of the soil sample turned black.

From the summary statistics in Table 5, it can be seen that the layer (5) of Shanghai clay samples have the most obvious shrinkage, with diameter shrinkage of $6.5 \%$ and the area shrinkage of $13 \%$, but no obvious cracks were observed on the surface of the clay samples. At this time, three relatively obvious cracks were observed on the surface of layer
(3) of Shanghai clay samples, but the secondary cracks were thinner and shorter than that of layer (2) of Shanghai clay samples. The diameter shrinkage rate of the samples was $4.1 \%$, the area shrinkage rate was $8 \%$, and the apparent color of the soil samples turned black.

The pore ratio of soil samples will change accordingly after shrinkage. The pore ratio of contaminated soil samples after shrinkage can be calculated by the following formula [28]. The porosity ratio of indoor soaking contaminated samples by TCE after interaction $t=379$ days is shown in Table 6

$$
e_{1}=e_{0}-\left(1+e_{0}\right) \frac{\Delta D}{D_{0}},
$$

where $e_{1}$ is the pore ratio of indoor soaked contaminated samples after shrinkage; $e_{0}$ is the pore ratio of clay sample before soaked; $\Delta D$ is the change of soil sample diameter before and after shrinkage, $\mathrm{cm}$; and $D_{0}$ is the diameter of clay sample before soaked, $\mathrm{cm}$.

2.3. Existing State of Organic Pollution. According to the method of Griffin and Watson [28, 29], the content of trichloroethylene detected in the clay samples was compared with the calculated value of $C_{\text {soil }}$ to determine whether there was a free phase of vinyl chloride in the contaminated clay. The calculation formula of $C_{\text {soil }}$ is as follows:

$$
\mathrm{C}_{\text {soil }}=\frac{\left(n+\rho_{b} K_{d}\right) C_{w s}}{\rho_{b}}
$$

Among them, $C_{w s}$ is the effective solubility of trichloroethylene in water, $\mathrm{mg} / \mathrm{L} ; K_{d}$ is the adsorption distribution coefficient, L/kg and $K_{d}$ can be estimated by the product of the organic carbon content $f_{o c}$ and the water/organic carbon distribution coefficient $k_{o c} ; f_{o c}$ is the product of the organic carbon content; $k_{o c}$ is the water/organic carbon distribution coefficient; the coefficient is calculated using the measured value of Shen Ting-ting [30], $n$ is the porosity, $\rho_{b}$ is the dry density, $\mathrm{g} / \mathrm{cm}^{3}$.

In this experiment, the clay samples of each soil layer were contaminated by vinyl chloride and 1, 1, 2-trichloroethane on site and the clay samples of the third and fourth layers contaminated with trichloroethylene soaked in indoor soil samples were investigated for volatile organic pollutants in contaminated clay content determination test.

From the results in Table 7 , it can be seen that the content of volatile pollutants measured in the contaminated clay under indoor TCE soaking pollution is higher than that in the clay under on-site vinyl chloride and 1, 1, 2-trichloroethane pollution. The pollutant content is obviously larger and varies from several times to ten times larger. From the results in Table 7 , it can be seen that the content of volatile pollutants measured in the contaminated clay under indoor TCE immersion pollution is higher than that in the clay under on-site vinyl chloride and 1, 1, 2-trichloroethane pollution. The pollutant content is obviously larger and varies from several times to ten times larger. This shows that the content of organic volatile pollutants in the contaminated clay samples under indoor TCE soaking pollution is 
TABLE 3: Soil layer distribution and basic physical and mechanical indexes.

\begin{tabular}{lcccccc}
\hline Soil layer & color & $\begin{array}{c}\text { soil depth H } \\
/ \mathrm{m}\end{array}$ & $\begin{array}{c}\text { Density } \rho \\
\mathrm{g} / \mathrm{cm}^{3}\end{array}$ & $\begin{array}{c}\text { moisture content } w \\
/ \%\end{array}$ & $\begin{array}{c}\text { void ratio } e \\
/\end{array}$ & $\begin{array}{c}\text { permeability coefficient } k * 10^{-7} \\
/ \mathrm{cm} / \mathrm{s}\end{array}$ \\
\hline Layer (2) & Grayish yellow & $2.4 \sim 2.7$ & 1.832 & 26.7 & 0.726 & 2.32 \\
Layer (3) & Grayish & $4.0 \sim 4.3$ & 1.822 & 44.8 & 1.223 & 5.24 \\
Layer (4) & Grayish & $12.5 \sim 12.8$ & 1.785 & 48.0 & 1.315 & 0.83 \\
Layer (5) & Grayish & $21.5 \sim 21.8$ & 1.765 & 48.8 & 1.342 & 1.73 \\
\hline
\end{tabular}

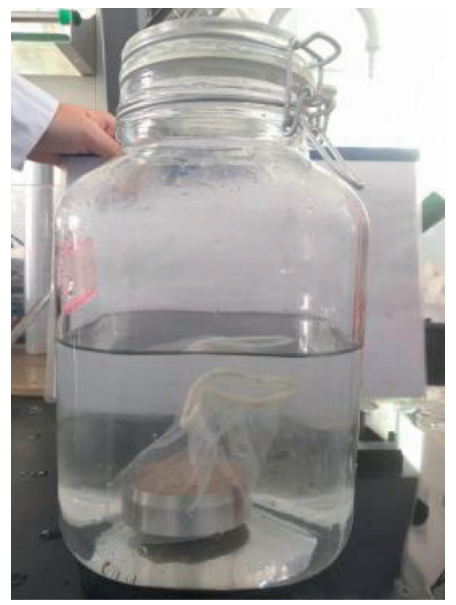

(a)

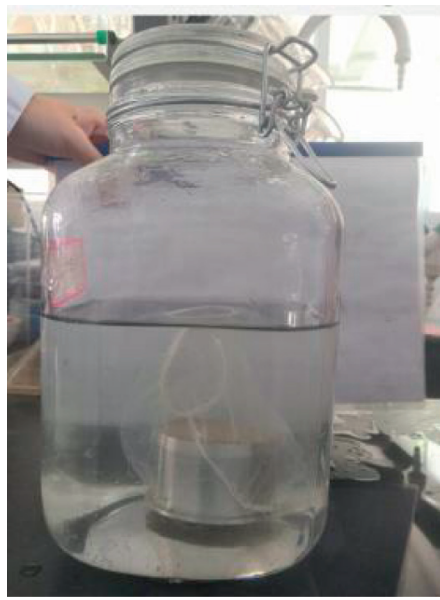

(b)

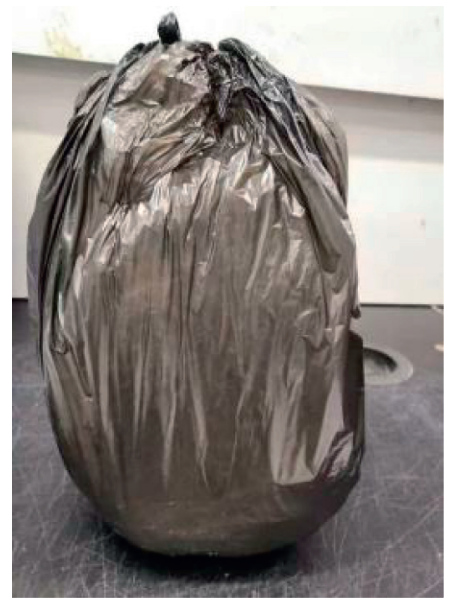

(c)

FIGURE 3: The picture of preparation of indoor soaking contaminated samples by TCE. (a) $2 \mathrm{~cm}$ ring knife soaked sample. (b) $4 \mathrm{~cm}$ ring knife soaked sample. (c) Sealed and stored away from light.

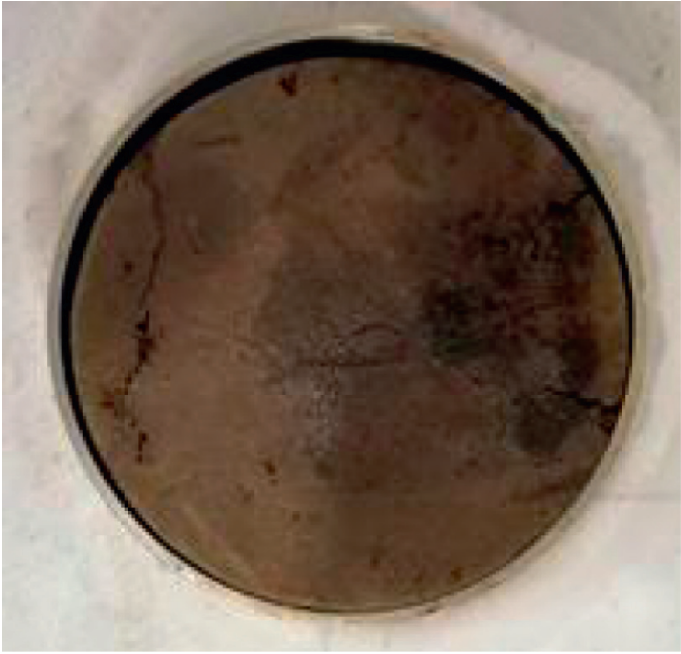

(a)

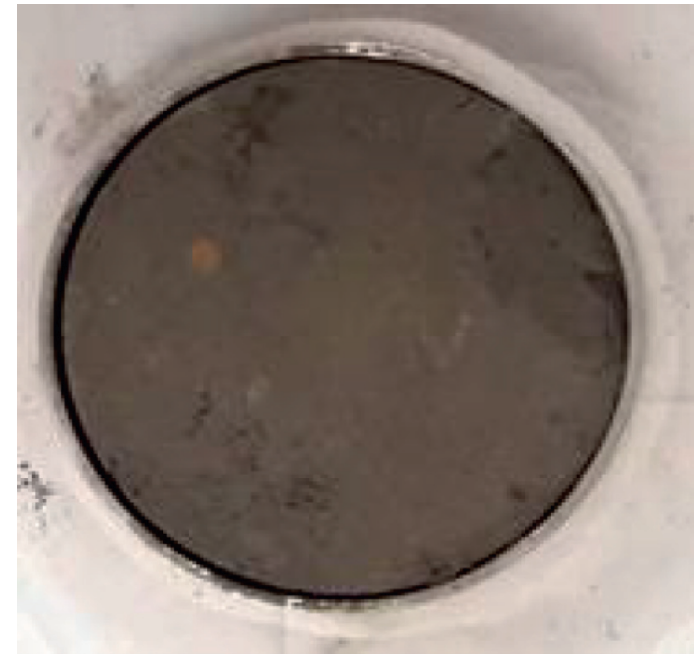

(b)

Figure 4: Continued. 


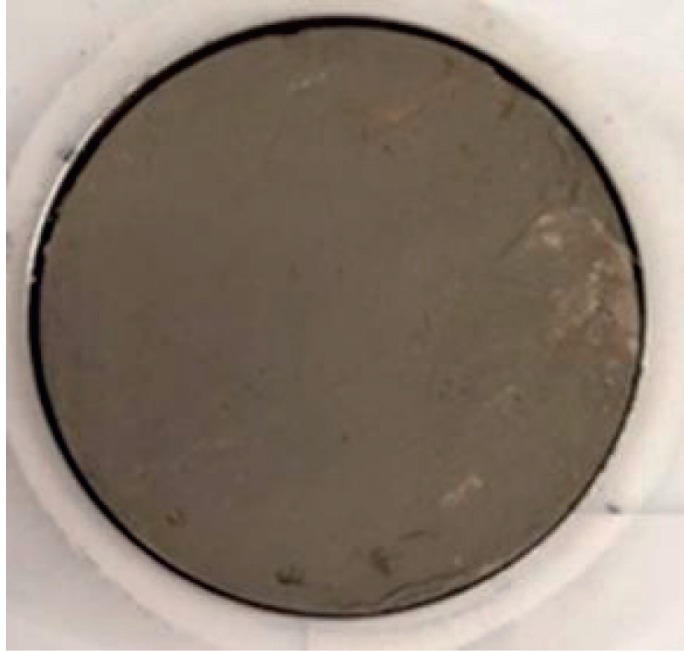

(c)

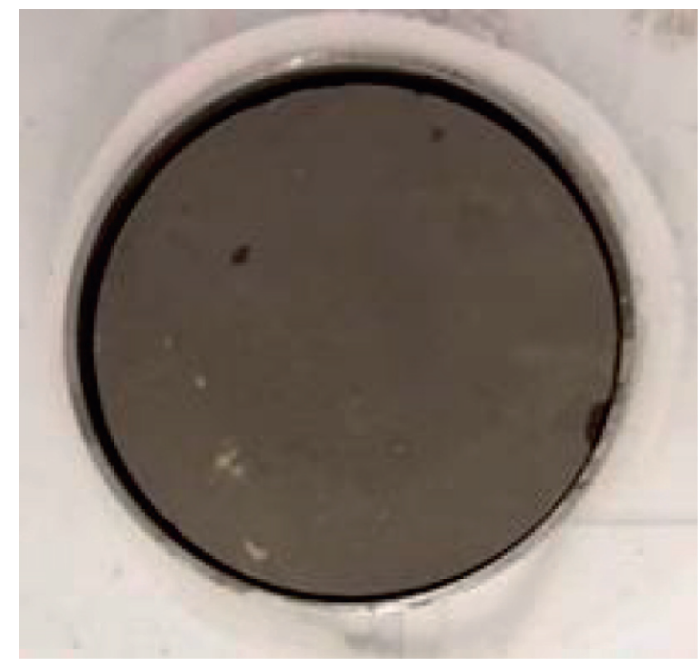

(d)

FIGURE 4: The changes in apparent characteristics of indoor soaked contaminated samples by TCE ( $t=212$ days). (a) Layer (2). (b) Layer (3). (c) Layer (4). (d) Layer (5).

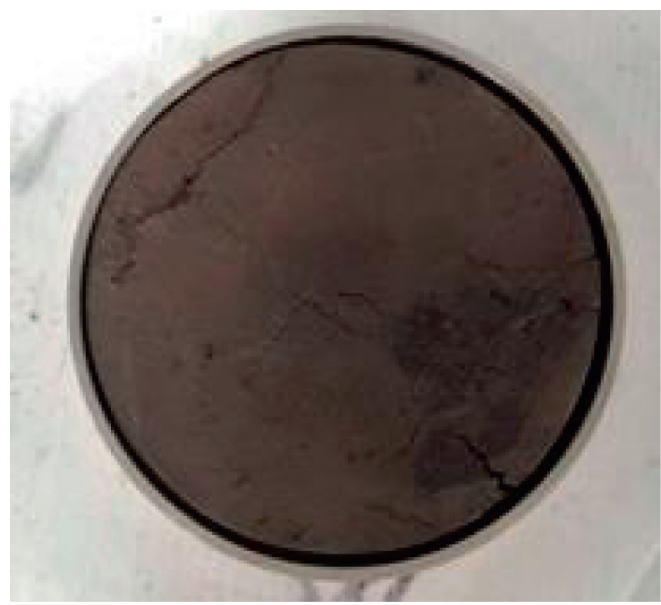

(a)

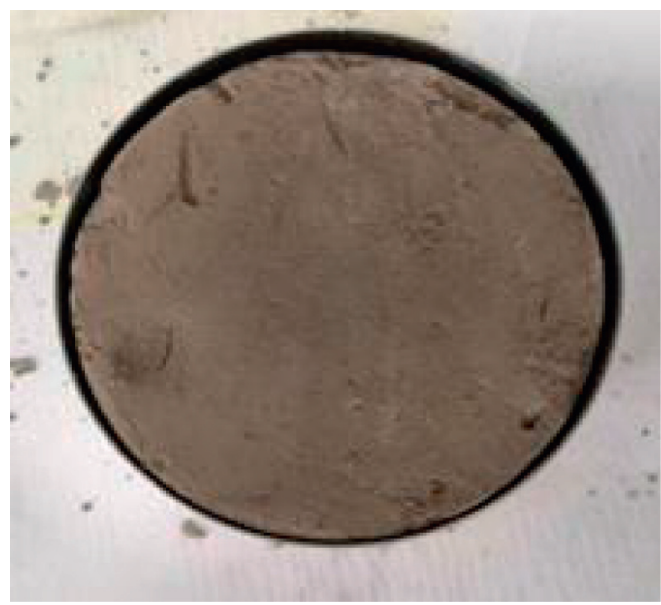

(c)

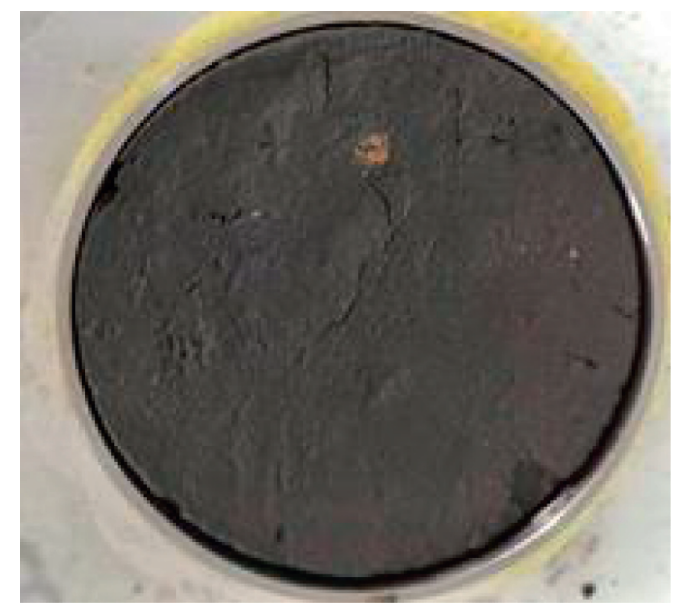

(b)

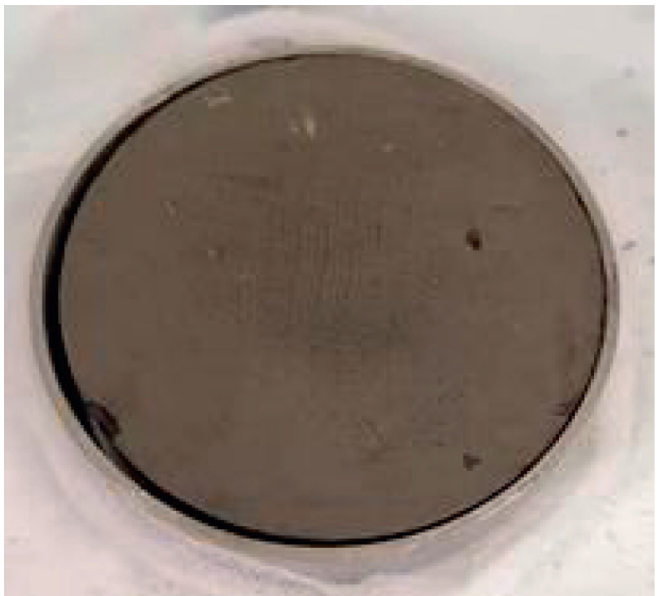

(d)

FIGURE 5: The changes in apparent characteristics of indoor soaked contaminated samples by TCE ( $t=379$ days). (a) Layer (2). (b) Layer (3). (c) Layer (4). (d) Layer (5). 
TABLE 4: Summary of changes in apparent characteristics of indoor soaked contaminated samples by TCE ( $t=212$ days).

\begin{tabular}{lccccc}
\hline Soil layer & $\mathrm{N}$ & $\mathrm{L}(\%)$ & $\mathrm{D}(\mathrm{cm})$ & $\mathrm{S}$ & The apparent color change of soil samples \\
\hline Layer (2) & 1 & 3.87 & 0.232 & 0.92 & Blackened significantly \\
Layer (3) & - & 2.20 & 0.132 & 0.96 & Blackened significantly \\
Layer (4) & - & 2.58 & 0.155 & 0.95 & Turn black \\
Layer (5) & - & 5.85 & 0.351 & 0.89 & Blackened significantly \\
\hline
\end{tabular}

TABLE 5: Summary of changes in apparent characteristics of indoor soaked contaminated samples by TCE ( $t=379$ days).

\begin{tabular}{lccccc}
\hline Soil layer & $\mathrm{N}$ & $\mathrm{L}(\%)$ & $\mathrm{D}(\mathrm{cm})$ & $\mathrm{S}$ & The apparent color change of soil samples \\
\hline Layer (2) & 1 & 1 & 4.92 & 0.295 & Blackened significantly \\
Layer (3) & - & 3 & 4.10 & 0.246 & Blackened significantly \\
Layer (4) & - & - & 5.82 & 0.349 & Turn black \\
Layer (5) & - & - & 6.50 & 0.390 & Blackened significantly \\
\hline
\end{tabular}

TABLE 6: Summary of changes in apparent characteristics of indoor soaked contaminated samples by TCE $(t=379$ days).

\begin{tabular}{lccccc}
\hline Soil layer & $e_{1}$ & $e_{0}$ & $\Delta D(\mathrm{~cm})$ & $D_{0}$ & e1/e0 \\
\hline Layer (2) & 1 & 1 & 4.92 & 0.295 & Blackened significantly \\
Layer (3) & - & 3 & 4.10 & 0.246 & Blackened significantly \\
Layer (4) & - & - & 5.82 & 0.349 & Turn black \\
Layer (5) & - & - & 6.50 & 0.390 & Blackened significantly \\
\hline
\end{tabular}

TABLe 7: Detected value of volatile organic pollutants and is there a free phase in the contaminated clay samples?

\begin{tabular}{|c|c|c|c|c|c|c|c|c|}
\hline soil samples & Soil layer & $n$ & $\rho_{b}$ & $K_{d}(\mathrm{~L} / \mathrm{kg})$ & $\begin{array}{c}C_{w s} \\
(\mathrm{mg} / \\
\mathrm{L})\end{array}$ & $\begin{array}{c}C_{\text {soil }} \\
(\mathrm{mg} / \mathrm{kg})\end{array}$ & $\begin{array}{l}\text { Detected value } \\
\quad(\mathrm{mg} / \mathrm{kg})\end{array}$ & $\begin{array}{c}\text { Have free } \\
\text { phase? }\end{array}$ \\
\hline \multirow{4}{*}{ The field contaminated soil samples of vinyl chloride } & Layer (2) & 0.496 & 1.375 & 7.94 & \multirow{4}{*}{2920} & 24238 & 143 & No \\
\hline & Layer (3) & 0.562 & 1.197 & 12.62 & & 38221 & 315 & No \\
\hline & Layer (4) & 0.586 & 1.139 & 13.35 & & 40484 & 981 & No \\
\hline & Layer (5) & 0.544 & 1.254 & 14.09 & & 42409 & 668 & No \\
\hline \multirow{4}{*}{ The field contaminated soil samples of $\mathrm{CH}_{2} \mathrm{ClCHCl}_{2}$} & Layer (2) & 0.496 & 1.375 & 7.94 & \multirow{4}{*}{4360} & 36191 & 143 & No \\
\hline & Layer (3) & 0.562 & 1.197 & 12.62 & & 57070 & 315 & No \\
\hline & Layer (4) & 0.586 & 1.139 & 13.35 & & 60449 & 981 & No \\
\hline & Layer (5) & 0.544 & 1.254 & 14.09 & & 63323 & 668 & No \\
\hline \multirow{2}{*}{ Indoor soaked contaminated clay of TCE } & Layer (3) & 0.531 & 1.286 & 12.62 & \multirow{2}{*}{1368} & 46209 & 2588 & No \\
\hline & Layer (4) & 0.567 & 1.177 & 13.35 & & 18922 & 4915 & No \\
\hline
\end{tabular}

higher. The existence of vertical and lateral forces limits the shrinkage of the clay sample so that the connection force between the soil bodies will not be significantly weakened. On the other hand, the pollutants intrude into the clay sample relatively less, so the content of organic volatile pollutants was low. For indoor TCE soaked contaminated clay, since the soaked clay sample is not affected by vertical and lateral forces, when TCE pollutants interact with the clay samples, trichloroethylene contaminants were more likely to intrude into the clay samples, resulting in higher levels of measured volatile organic pollutants.

According to the analysis of the test results, there is no free phase of pollutants in both indoor soaked and on-site contaminated soil, but the detected value of volatile pollutants in indoor trichloroethylene soaking contaminated soil is higher than that in the same layer of on-site contaminated soil. This indicates that in the case of indoor soaked pollutants, when the soil is not subjected to the vertical initial stress, the pollutants are more likely to invade into the soil than that in the on-site contaminated soil. It was also found that the clay has obvious shrinkage and cracking phenomenon in the laboratory experiment of soaking pollution of the last section. The results indicate that the contaminants would have a certain influence on the structure and migration of clay.

From the analysis of the test results, it can be seen that neither the indoor contaminated soil soaked in TCE nor the contaminated soil on site contains a free phase of pollutants. However, the detection value of volatile pollutants in indoor TCE-soaked polluted soil was higher than that of organic volatile pollutants in field polluted soil. This shows that under indoor soaking pollution, with the passage of interaction time, when the clay sample is not subjected to vertical initial stress, the pollutants are more likely to invade the soil 
body. And from Section 2.2, it can be seen that the indoor TCE soaked contaminated clay samples will produce obvious shrinkage and cracking phenomena under the longterm interaction with TCE. This shows that the intrusion of pollutants into the contaminated clay samples will have a certain impact on the structural characteristics, permeability characteristics, and migration characteristics of the contaminated clay samples.

\section{Permeability}

3.1. Permeability Test Method. In this paper, two types of permeability test methods are used. The first type is the use of ring knife samples. The permeability test research was carried out by using a conventional variable head permeability device and a permeability test device under hydraulic control. This test method is mainly for field contaminated clay samples and uncontaminated clay samples because these clay samples can also be prepared into ring knife samples with a $4 \mathrm{~cm} * 30 \mathrm{~cm}^{2}$ ring knife. This is because whether it is a contaminated clay sample or an uncontaminated clay sample, as long as it can be prepared into a ring knife sample, the rigid wall permeability test device can be used to measure the permeability coefficient. If the clay sample cannot be prepared into a ring-knife sample due to shrinkage or cracking, etc., this method cannot be used to measure the permeability coefficient. So, for the indoor TCE soaked samples, the second type of permeability test method is mainly used. That is, the permeability coefficient is measured using an improved rigid wall permeability test device. This method is used because the clay samples after indoor TCE are soaked and pollution will shrink and crack to different degrees. For the contaminated samples after shrinkage and cracking, the rigid wall permeability test device cannot be directly used to measure the permeability coefficient. Therefore, the team independently developed rigid-wall permeability test device was used to conduct permeability tests. The schematic diagrams of the self-developed permeation cavity devices with improved walls are shown in Figure 6.

The improved rigid wall permeability test device consists of three parts: the top cover, the base, and the soil sample chamber. Among them, the main function of the top cover is to prevent the clay-like bulge wrapped by the rubber film; there is a lateral pressure sensor on the sidewall, which is mainly used to control the lateral pressure. The control valve is connected to the hydraulic controller.

The permeability tests can be performed by applying osmotic pressure. The soil sample cavity can carry out the permeability test on the clay sample with a height of $2 \sim 6 \mathrm{~cm}$. When the height of the soil sample is low, the top and bottom of the soil sample can be filled with permeable cushion stones with high water permeability. Since the side walls are rubber membranes; therefore, there is no requirement for the area of the clay sample to be tested in this test, and only the rubber membrane of the corresponding area needs to be prepared. Therefore, the permeability test of the shrunk or cracked contaminated clay sample by this method is effective.
When conducting the improved rigid wall penetration test, the test device needs to be vented as in the traditional rigid wall penetration test. At this time, it was also necessary to fill the space between the rubber film and the test cavity device with water to form a flexible wall environment. Then, by applying a certain lateral pressure, the soil samples and the rubber mold are tightly combined to prevent the gap between the clay body and the sidewall of the ring knife in the rigid wall device. As a result, the penetration is measured more accurately and reliably. In order to prevent the measured permeability coefficient from being smaller than the actual situation due to excessive lateral pressure, when conducting the modified rigid wall permeability test, the set value of confining pressure in the test is $20 \mathrm{kpa}$, and the set value of osmotic pressure is under $10 \mathrm{kpa}$.

Since the device is carried out under hydraulic control, which ensures that the permeate head is under a certain pressure, it is similar to the constant head test. When the height of the soil sample is $L$, the cross-sectional area is $A$, and the height of the water head under osmotic pressure is $h$, at a certain time $t$, the flow through the soil sample is $Q$, so the permeability coefficient $k$ of the unearthed sample is as follows:

$$
k=\frac{Q L}{A h t},
$$

where $k$ is the permeability coefficient, $\mathrm{cm} / \mathrm{s}$; $Q$ is the flow through the soil samples within a certain time $t, \mathrm{~mL} ; L$ is the soil sample height, $\mathrm{cm} ; A$ is soil sample area, $\mathrm{cm}^{2} ; h$ is the head height under hydraulic control, $\mathrm{cm}$; $t$ is the permeability time, $s$.

3.2. Permeability Coefficient. In order to more comprehensively study and analyze the changes in the permeability characteristics of the field contaminated clay samples by vinyl chloride and 1, 1,2trichloroethane pollutions, a permeability test was carried out on the field contaminated samples: rigid wall permeability test (under $10 \mathrm{kpa}$ permeability pressure). At the same time, the uncontaminated clay samples were also subjected to the permeability test using the same device: rigid wall permeability test (under10 kpa permeability pressure). The test results are shown in Table 8 . The test results show that, after being polluted by vinyl chloride and 1,1,2-trichloroethane pollutants, the permeability coefficient of the contaminated soil increases compared with the uncontaminated clay, but there is no obvious change.

For indoor TCE soaked contaminated samples, due to the shrinkage and cracking of the soaked contaminated clay samples, an improved rigid wall permeability test device was used to measure the permeability coefficient (under the confining pressure $20 \mathrm{kpa}$ and the osmotic pressure $10 \mathrm{kpa}$ ). Since long-term interaction tests were carried out, permeability tests were performed on contaminated clay samples ( $t=379$ days and $t=522$ days) under different soaked contamination times. The test results show that with the passage of soaked pollution time, the permeability coefficient of indoor TCE soaked polluted clay increases. Although 


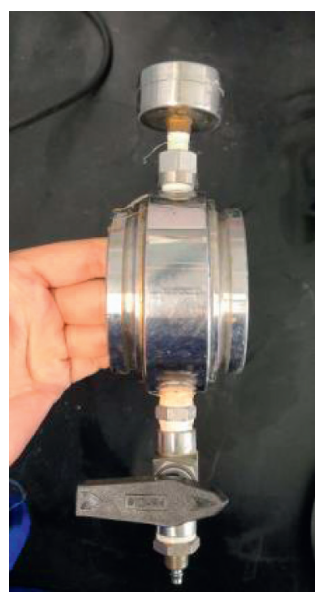

(a)

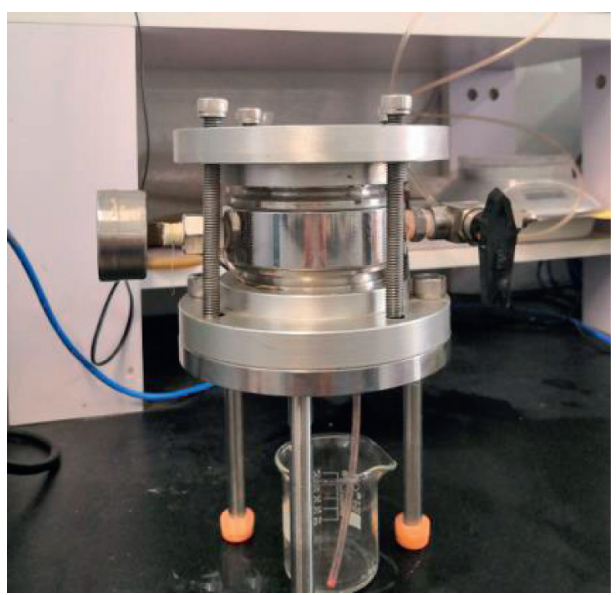

(d)

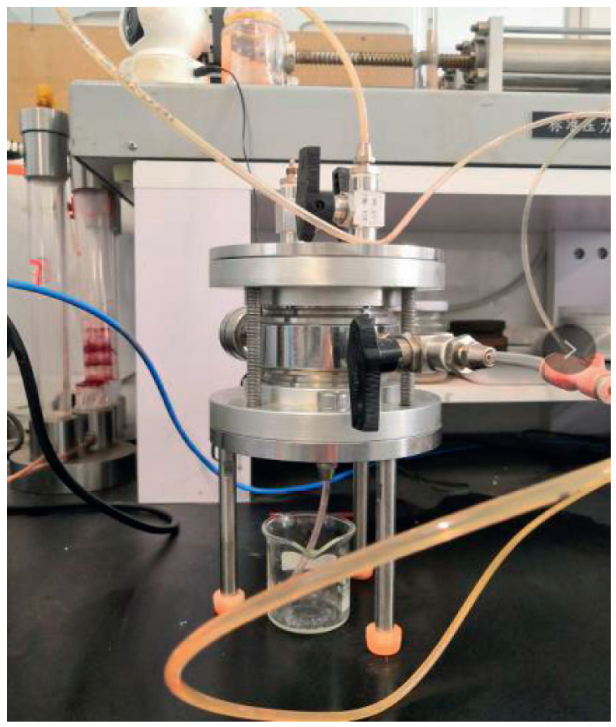

(f)

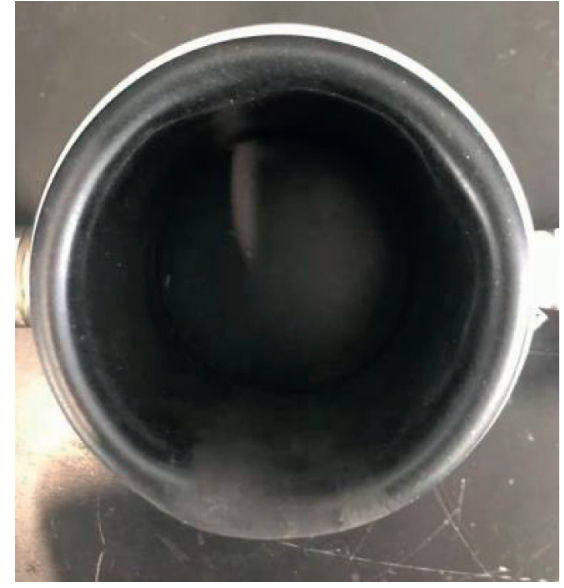

(b)

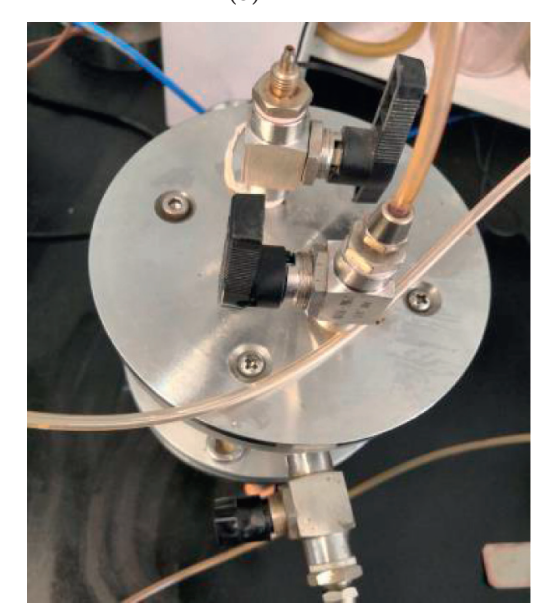

(e)

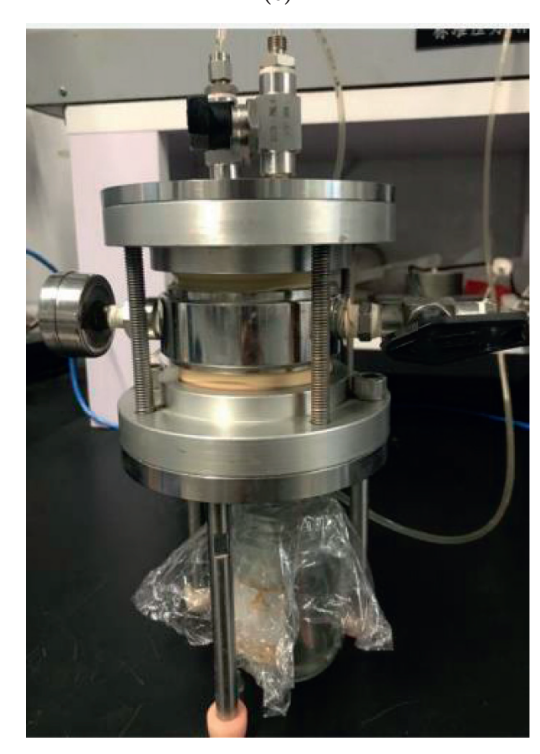

(g)

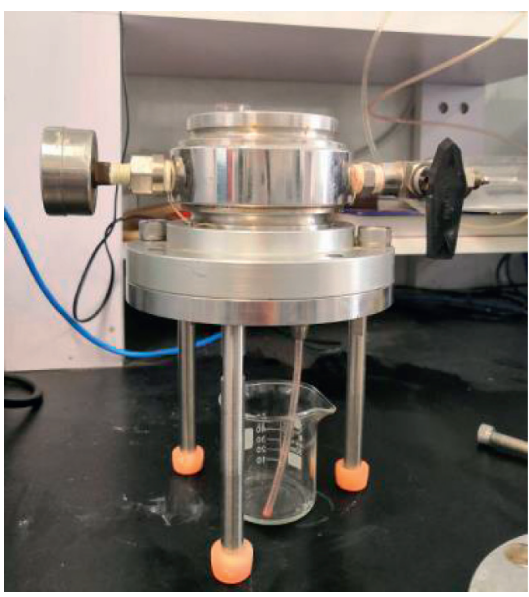

(c)

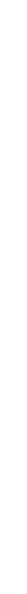
FIGURE 6: Improved rigid wall permeability test device and operation steps. (a) Sample chamber. (b) Set up rubber membrane. (c) Place the soil sample chamber on the base. (d) Adjust the confining pressure to place the soil sample to be tested. (e) Tighten the bolts around the top cover. (f) Open the top cover vent valve for venting. (g) Conduct a permeability test. 
TABLE 8: Permeability test results of contaminated and uncontaminated soil samples.

Permeability coefficient $k\left(10^{-7 \mathrm{~cm} / \mathrm{s}}\right)$

\begin{tabular}{|c|c|c|c|c|c|c|c|}
\hline \multirow{3}{*}{ Soil layer } & \multicolumn{7}{|c|}{ Permeability coefficient $k\left(10^{-7 \mathrm{~cm} / \mathrm{s}}\right)$} \\
\hline & \multirow[t]{2}{*}{ uncontaminated clay $k_{0}$ rigid wall } & \multirow{2}{*}{$\begin{array}{l}\text { The field contaminated soil rigid wall } k_{1} \\
\qquad t=0 \mathrm{~d}\end{array}$} & \multicolumn{2}{|c|}{$\begin{array}{c}\text { Indoor soaking } \\
\text { contaminated clay } \\
k_{2}(t=522 \mathrm{~d}) \\
\text { Improved rigid } \\
\text { walls }\end{array}$} & \multirow{2}{*}{$\begin{array}{c}k_{1} / k_{0} \\
- \\
-\end{array}$} & \multirow{2}{*}{$\begin{array}{c}k_{2} / k_{0} \\
- \\
-\end{array}$} & \multirow{2}{*}{$\begin{array}{r}k_{2} / k_{1} \\
- \\
-\end{array}$} \\
\hline & & & $t=379 \mathrm{~d}$ & $t=522 \mathrm{~d}$ & & & \\
\hline Layer (2) & 2.32 & 3.01 & - & - & 1.297 & - & \\
\hline Layer (3) & 5.24 & 6.37 & 7.71 & 8.03 & 1.215 & 1.532 & 1.261 \\
\hline Layer (4) & 0.83 & 1.67 & 1.34 & 1.52 & 2.012 & 1.831 & 0.910 \\
\hline Layer (5) & 1.73 & 1.84 & - & - & 1.064 & - & - \\
\hline
\end{tabular}

there is no obvious change at the level of magnitude, the permeability coefficient of indoor TCE soaked contaminated clay increased more significantly.

Combined with the laboratory test results in Sections 2.2 and 2.3 , it can be seen that no free phase was detected in the soil samples contaminated with vinyl chloride and 1, 1, 2trichloroethane, and no cracks and shrink were visible on the surface of the clay. Although the free phase was not detected in the contaminated clay samples soaked in trichloroethylene, with the passage of interaction time, obvious shrinkage and cracks were observed in the clay samples, but no observation was observed until $t=522$ days. It can be seen that NAPL pollutants are more likely to be poured into the clay without initial stress and no lateral stress, which is related to the characteristics of the pollutants and the interaction time and is more related to the change of the microstructural characteristics of the polluted clay itself. Therefore, specific research and analysis of this feature are required.

It can be seen from Table 8 and Figure 7 that under the interaction of NAPL organic pollutants, whether it is the field contaminated soil samples or the indoor TCE soaked contaminated clay samples, the permeability coefficient of the contaminated clay sample shows an increasing trend, but the change does not show a trend of increasing order of magnitude. Among them, the ratio of the permeability coefficient of the contaminated soil to that of the uncontaminated soil is about 1.2 2.0. The permeability coefficient of indoor TCE-contaminated clay is larger than that of onsite polluted soil. The ratio of permeability coefficient of indoor TCE-soaked polluted soil to that of on-site polluted soil is about $1.0 \sim 1.2$.

From the results of the apparent observation test, it can be seen that under the interaction between the pollutant and the clay sample, with the passage of time, only a distinct pungent smell the contaminated clay sample was smelled in the odor, but the appearance was not intuitive. Significant changes were observed. In the indoor TCE soaked test, the clay samples have different degrees of shrinkage and cracking. This is due to the long-term interaction, the contamination pollutant intrudes into the clay samples and interacts with the samples. As a result, the original "dense" structure changes, and the soil particles also change to a "flocculated" state. Therefore, it can better prove that the permeability coefficient of indoor soaked contaminated soil is greater than that of field contaminated soil.
From the determination of the free phase content in the contaminated clay in Section 2.3, it can be seen that the free phase of pollutants was not found in both the field contaminated soil and the indoor TCE soaked contaminated clay. The permeability coefficients of the polluted soils on the site all showed an increasing trend, but the changes were not obvious and did not show a trend of the order of magnitude increase. Under the indoor TCE soaking test, the content of pollutants in the clay body is not enough to increase the permeability coefficient of soil samples by several orders of magnitude. Therefore, it is necessary to combine the microstructure test results to comprehensively analyze the influence of NAPL pollutants on the microstructure and permeability characteristics of the soil samples after invading the clay samples.

\section{Microstructure Results of Contaminated Soil Samples}

4.1. Results of Pore-Size Distribution Test. The contaminated soil from layers (2)-(5) on site and the clay from the (4) layer of indoor TCE soaked contaminated soil are selected for microstructure test. The values of parameters such as the porosity of the clay body obtained from the test are shown in Table 9. The Hodot method [31-34]was used for pore size classification (macro-pores $d>1000 \mathrm{~nm}$, mesopores $100<d<1000 \mathrm{~nm}$, transition pores $10<d<100 \mathrm{~nm}$, micropores $d<10 \mathrm{~nm}$ ), the obtained relationship between the pore size of different grades and the cumulative pore volume and the relationship between the mercury injection volume increment and the pore diameter are shown in Figure 8.

From the test results in Table 9, it can be seen that compared with the uncontaminated saturated clay, the total mercury injection volume and the average pore diameter of the field contaminated soil showed an overall increasing trend, and the total porosity also showed an overall increasing trend. At the same time, it was found that the total mercury injection volume, average pore diameter, and total porosity of the clay samples in layer (4) under indoor TCE soaking contaminated were larger than those in layer (4) contaminated with vinyl chloride. This shows that in the same layer (4) clay sample, the microstructure damage of indoor TCE-soaked contaminated clay is more significant than that of field contaminated clay. This point is also consistent with the discussion in the previous sections that 


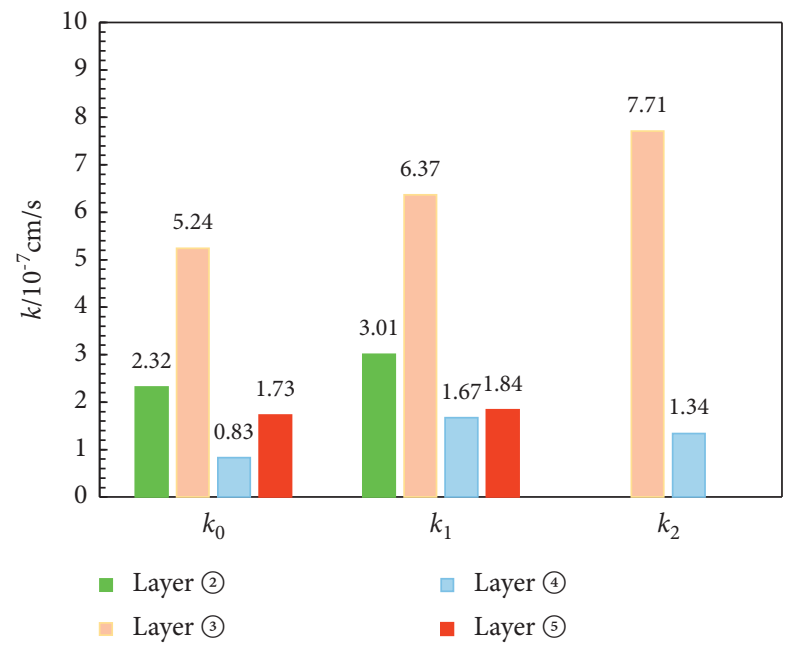

Figure 7: Correlation diagram of permeability coefficient between contaminated and uncontaminated clay.

TABLE 9: Changes of clay porosity between TCE contaminated soils and uncontaminated soils.

\begin{tabular}{|c|c|c|c|c|c|c|}
\hline \multirow[b]{2}{*}{ Soil samples } & \multirow{2}{*}{$\begin{array}{c}\text { Soil } \\
\text { layer }\end{array}$} & \multicolumn{5}{|c|}{ The result value of mercury intrusion } \\
\hline & & $\begin{array}{c}\text { sample } \\
\text { weight }(\mathrm{g})\end{array}$ & $\begin{array}{l}\text { total volume of } \\
\text { mercury }(\mathrm{mL} / \mathrm{g})\end{array}$ & $\begin{array}{l}\text { total pore surface } \\
\text { area }\left(\mathrm{m}^{2} / \mathrm{g}\right)\end{array}$ & $\begin{array}{l}\text { average pore } \\
\text { diameter }(\mu \mathrm{m})\end{array}$ & $\begin{array}{c}\text { Porosity } \\
(\%)\end{array}$ \\
\hline \multirow{4}{*}{ Uncontaminated clay } & $\begin{array}{l}\text { Layer } \\
(2)\end{array}$ & 1.1792 & 0.2159 & 9.2350 & 0.0935 & 35.5756 \\
\hline & $\begin{array}{c}\text { Layer } \\
(3)\end{array}$ & 0.7899 & 0.4876 & 6.0540 & 0.3222 & 54.2128 \\
\hline & $\begin{array}{l}\text { Layer } \\
(4)\end{array}$ & 0.8404 & 0.3876 & 16.0010 & 0.0969 & 48.9643 \\
\hline & $\begin{array}{c}\text { Layer } \\
(5)\end{array}$ & 0.7328 & 0.3823 & 12.3330 & 0.1240 & 49.9791 \\
\hline \multirow{4}{*}{$\begin{array}{l}\text { The filed contaminated clay of vinyl } \\
\text { chloride and } \mathrm{CH}_{2} \mathrm{ClCHCl}_{2}\end{array}$} & $\begin{array}{l}\text { Layer } \\
(2)\end{array}$ & 0.7379 & 0.3518 & 14.3610 & 0.9799 & 46.8538 \\
\hline & $\begin{array}{l}\text { Layer } \\
\text { (3) }\end{array}$ & 0.7074 & 0.5345 & 4.9380 & 0.4330 & 53.3527 \\
\hline & $\begin{array}{c}\text { Layer } \\
(4)\end{array}$ & 0.8290 & 0.3576 & 12.5630 & 0.1138 & 49.1841 \\
\hline & $\begin{array}{l}\text { Layer } \\
(5)\end{array}$ & 0.7556 & 0.4165 & 18.8110 & 0.8857 & 51.6281 \\
\hline $\begin{array}{l}\text { Indoor soaked contaminated clay of } \\
\text { TCE }\end{array}$ & $\begin{array}{c}\text { Layer } \\
(4)\end{array}$ & 0.8904 & 0.4000 & 7.882 & 0.2030 & 50.7780 \\
\hline
\end{tabular}

under indoor soaked contaminated conditions, the measured content of volatile pollutants in TCE pollutants is higher, the permeability coefficient increases more, and the clay sample produces more obvious shrinkage and cracking.

It can be seen from Figure 8 that the volume increment of mercury injection in the pore diameter range of $\mathrm{d}>1000 \mathrm{~nm}$ of the clay sample after immersion in trichloroethylene is significantly increased, while the increment of the attack volume in the range of pore diameter $10<\mathrm{d}<100 \mathrm{~nm}$ is significantly reduced. It also can be seen that after the undisturbed clay samples of layer (4) of Shanghai were soaked in the TCE-contaminated pollutions, the diameter of the large pores of the samples increased, and the small pores decreased. Among them, in each pore diameter distribution range, the pore volume ratio of the particle size group is shown in Table 10. From the statistical data in Table 10, it can be seen that under the indoor TCE immersion pollution, the cumulative pore volume of the clay body increases, the percentage of large pore diameter increases from $57.59 \%$ before pollution to $60.32 \%$, and the diameter of medium and large pores increases. The total percentage increased from $87.24 \%$ to $89.33 \%$.

It can also be seen from the pore size distribution test results in Figure 8 that the volume increment of mercury injection in the range of $d>1000 \mathrm{~nm}$ in the pore diameter of the clay sample after NAPL pollution increases significantly. Among them, the uncontaminated clay sample of the Shanghai layer (2) has the most obvious increase in the diameter of macropores after being polluted by NAPL, and the volume of macropores in this macropore particle group has nearly doubled compared with the uncontaminated soil from the original $36.71 \%$ increased to $60.32 \%$. 

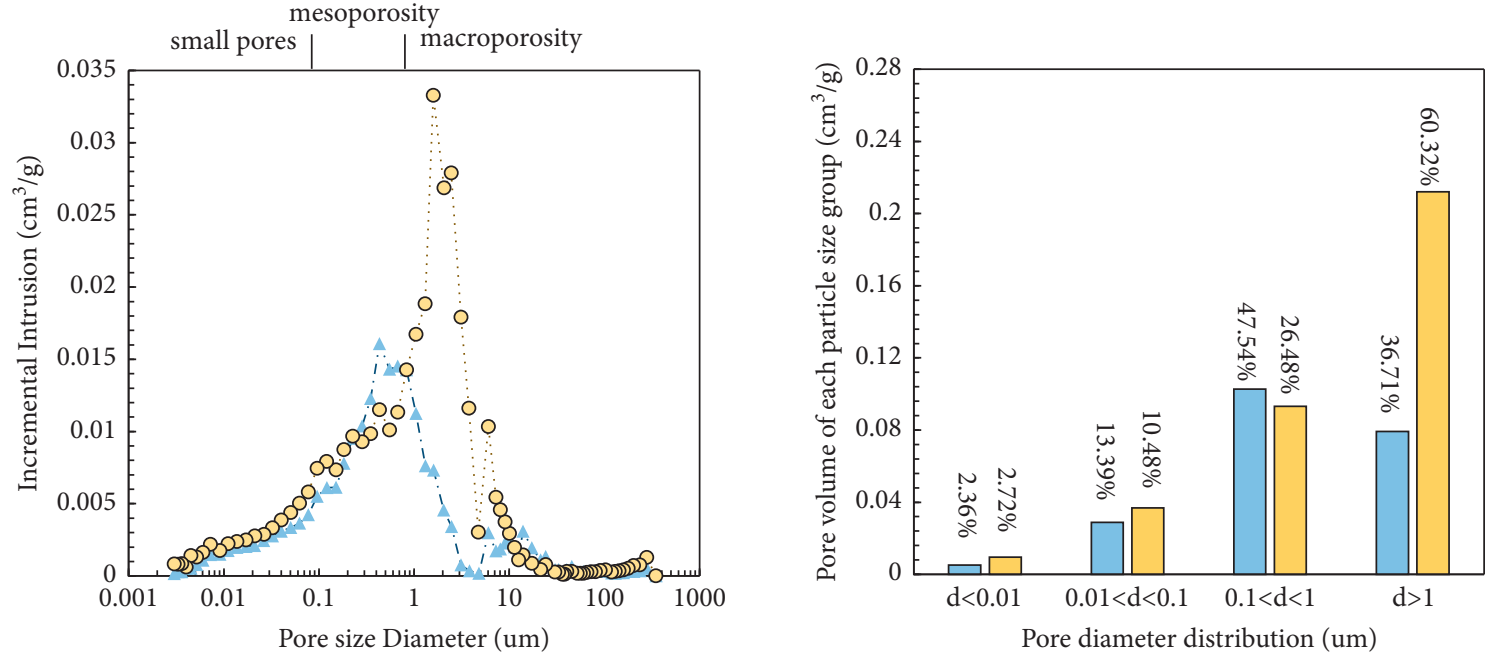

Layer (2)

- - - uncontaminated clay samples

.. o. The filed contaminated clay samples

Layer (2)

$\square$ uncontaminated clay samples

$\square$ The filed contaminated clay samples

(a)
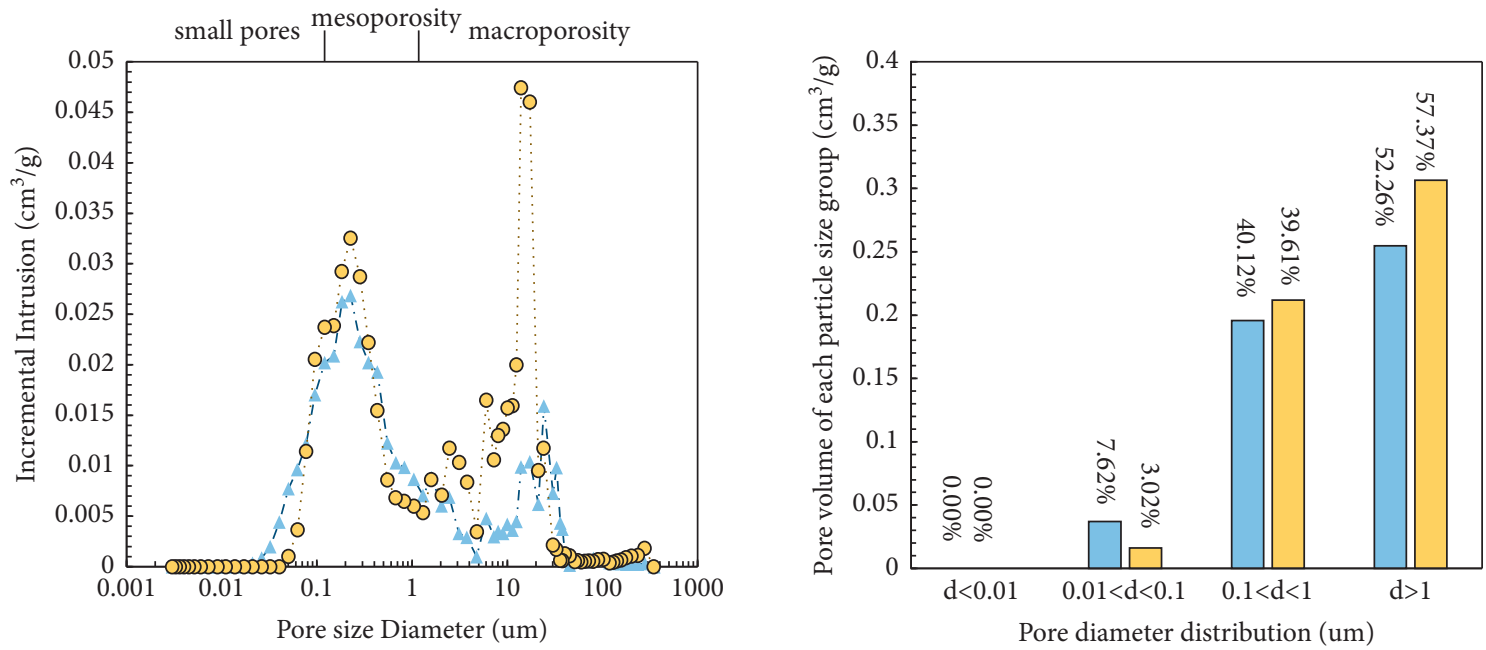

Layer (3)

- - uncontaminated clay samples

Layer (3)

๑ uncontaminated clay samples

. o. The filed contaminated clay samples

$\square$ The filed contaminated clay samples

(b)

Figure 8: Continued. 

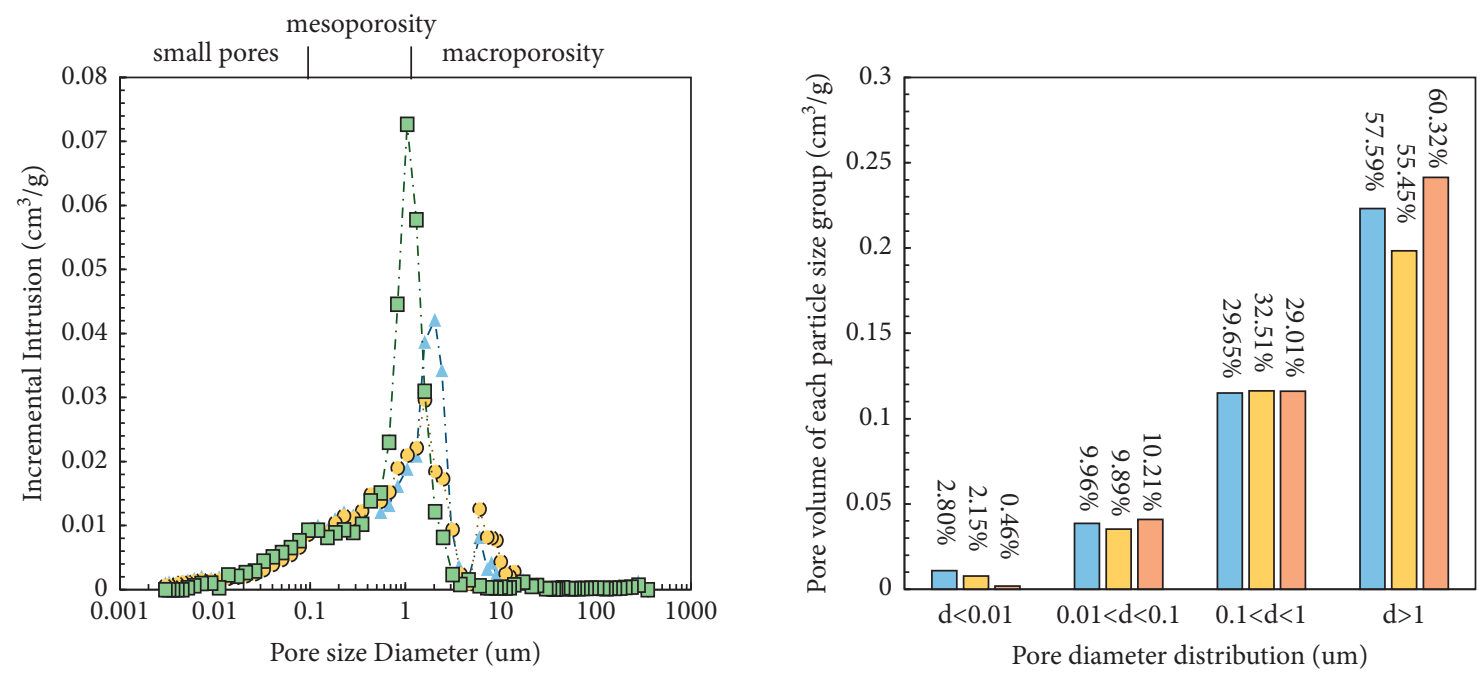

Layer (4)

-1:- uncontaminated clay samples

o.. The filed contaminated clay samples

$\checkmark-$ Indoor soaked contaminated clay samples

(c)
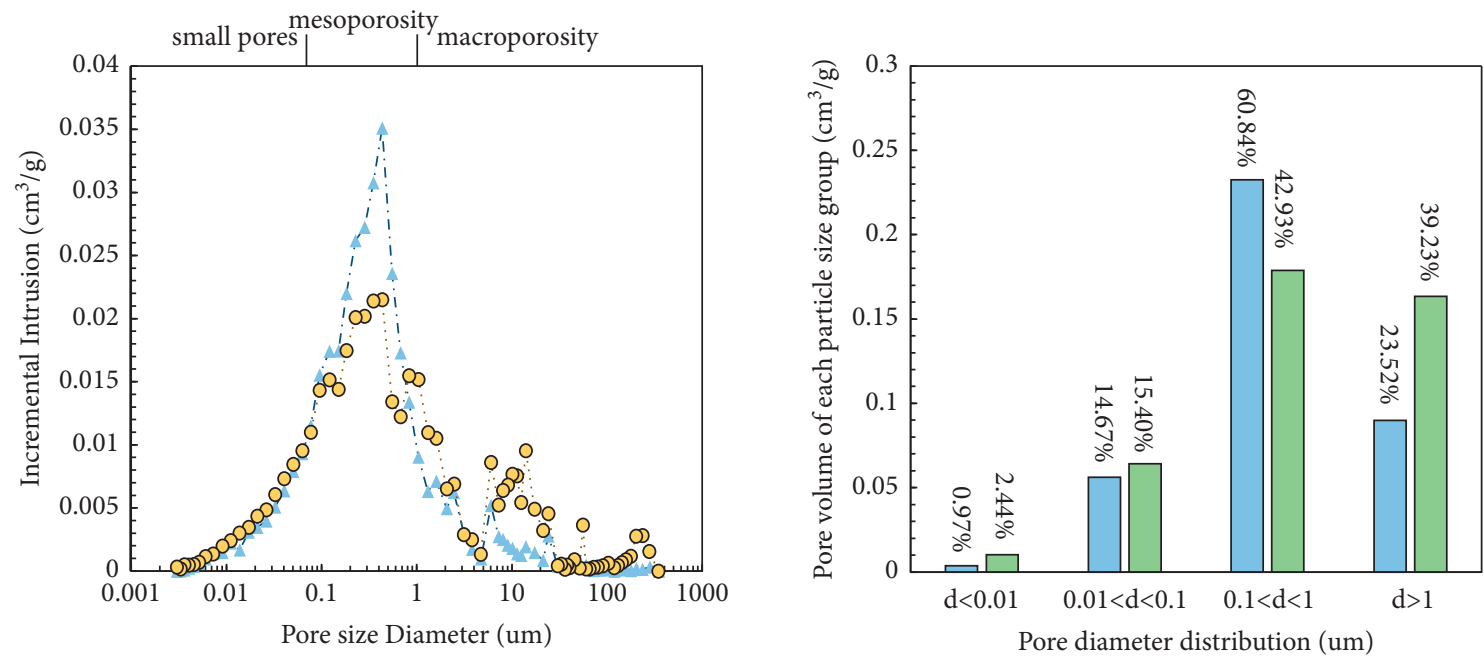

Layer (5)

Layer (5)

- - - uncontaminated clay samples

... The filed contaminated clay samples

¿ uncontaminated clay samples

The filed contaminated clay samples

(d)

Figure 8: Pore size distribution of contaminated and uncontaminated samples. (a) Layer (2). (b) Layer (3). (c) Layer (4). (d) Layer (5).

It can be seen from the test results in Table 10 that the cumulative pore volume of the contaminated clay and the percentage of pore volume in the range of large pore diameters are larger than those of the uncontaminated clay. Among them, the percentage of the macro-porous pore volume of the layer (2) of on-site polluted soil is about $60 \%$, and that of uncontaminated clay is only $36.71 \%$; the percentage of the macroporous pore volume of the layer (3) of on-site polluted soil is $57 \% \sim 62 \%$ The macropore volume percentage of the uncontaminated clay is about $52 \%$; The increase of the macropore volume percentage of the contaminated soil in the fourth layer is not obvious; the macropore volume percentage of the contaminated soil in the fifth layer is about $40 \%$, while the macropore volume percentage of uncontaminated clay is only $23 \%$. This shows that the pore structure distribution of the clay body after being polluted by NAPL changes obviously, and the proportion of large pores increases.

Moreover, the cumulative pore volume of contaminated samples by TCE is larger than that of uncontaminated clay when the pore diameter is greater than $1 \mathrm{um}$, which may reflect that under the interaction of TCE pollutants and clay 
TABLE 10: The percentage of pore volume and cumulative surface area of contaminated and uncontaminated samples.

\begin{tabular}{|c|c|c|c|c|c|c|c|}
\hline \multirow[b]{2}{*}{ Soil samples } & \multirow[b]{2}{*}{$\begin{array}{l}\text { Soil } \\
\text { layer }\end{array}$} & \multirow[b]{2}{*}{$\begin{array}{l}\text { accumulation } \\
\text { surface area } \\
\quad\left(\mathrm{m}^{2} / \mathrm{g}\right)\end{array}$} & \multirow{2}{*}{$\begin{array}{c}\text { cumulative } \\
\text { porosity } \\
\text { volume }\left(\mathrm{cm}^{3} /\right. \\
\mathrm{g})\end{array}$} & \multicolumn{4}{|c|}{ Percentage of pore volume (\%) } \\
\hline & & & & $\begin{array}{c}\text { Microporosity } \\
\mathrm{d}<10 \mathrm{~nm}\end{array}$ & $\begin{array}{l}\text { transition pores } \\
10<\mathrm{d}<100 \mathrm{~nm}\end{array}$ & $\begin{array}{c}\text { Mesoporosity } \\
100<\mathrm{d}<1000 \mathrm{~nm}\end{array}$ & $\begin{array}{l}\text { Macro-porosity } \\
\mathrm{d}>1000 \mathrm{~nm}\end{array}$ \\
\hline \multirow{4}{*}{ Uncontaminated clay } & $\begin{array}{c}\text { Layer } \\
\text { (2) }\end{array}$ & 9.24 & 0.216 & 2.36 & 13.39 & 47.54 & 36.71 \\
\hline & $\begin{array}{c}\text { Layer } \\
(3)\end{array}$ & 6.05 & 0.488 & 0 & 7.62 & 40.12 & 52.26 \\
\hline & $\begin{array}{c}\text { Layer } \\
(4)\end{array}$ & 16.00 & 0.388 & 2.80 & 9.96 & 29.65 & 57.59 \\
\hline & $\begin{array}{l}\text { Layer } \\
\text { (5) }\end{array}$ & 12.33 & 0.382 & 0.97 & 14.67 & 60.84 & 23.52 \\
\hline \multirow{4}{*}{$\begin{array}{l}\text { The filed contaminated } \\
\text { clay of vinyl chloride } \\
\text { and } \mathrm{CH}_{2} \mathrm{ClCHCl}_{2}\end{array}$} & $\begin{array}{l}\text { Layer } \\
(2)\end{array}$ & 14.36 & 0.352 & 2.72 & 10.48 & 26.48 & 60.32 \\
\hline & $\begin{array}{c}\text { Layer } \\
\text { (3) }\end{array}$ & 4.94 & 0.535 & 0 & 3.02 & 39.61 & 57.37 \\
\hline & $\begin{array}{c}\text { Layer } \\
\text { (4) }\end{array}$ & 12.56 & 0.358 & 2.15 & 9.89 & 32.51 & 55.45 \\
\hline & $\begin{array}{c}\text { Layer } \\
\text { (5) }\end{array}$ & 18.81 & 0.417 & 2.44 & 15.40 & 42.93 & 39.23 \\
\hline $\begin{array}{l}\text { Indoor soaked } \\
\text { contaminated clay of } \\
\text { TCE }\end{array}$ & $\begin{array}{l}\text { Layer } \\
(4)\end{array}$ & 7.88 & 0.400 & 0.46 & 10.21 & 29.01 & 60.32 \\
\hline
\end{tabular}

samples, soil pollution occurs. During flocculation, soil particles aggregate, and small pores gradually flocculate into mesopores, which gradually evolve into macropores. As a result, the content of mesopores and macropores tends to increase, while the content of small pores decreases. The next step will be further analyzed in combination with SEM results.

4.2. SEM Microstructure Test. Since layer (4) of saturated clay in Shanghai has been subjected to both indoor soaked by TCE, the permeability and pore size distribution tests were measured $[35,36]$ in order to explore the different changes of the microstructural properties effect on the same layer of saturated clay by the NAPL. In this paper, the Shanghai layer (4) samples were taken as an example to explore the change of the microstructure characteristics of the samples under the long-term interaction between saturated samples and NAPL.

Figure 9 shows the SEM test results at 500 times and 1500 times magnification. From the test results, it can be seen that after being contaminated by NAPL, the microstructure of the clay sample has changed significantly, the soil structure has become more dispersed, and the phenomenon of "flocculation" was more obvious. For the field contaminated soil, it can be intuitively observed that the number of pores in layer (4) of clay after being contaminated increases, and the pore volume also shows an obvious increasing trend. At the same time, for the contaminated clay soaked by TCE, the flocculation phenomenon of the contaminated clay sample is intensified, the number of pores between the aggregates increases, and the pore diameter slightly increase, which was also consistent with the increase in the cumulative pore volume obtained by the pore size distribution test, and the large pore volume is $100 \%$. The results of the experiments with no obvious increase in the content of the subcomponents are consistent with each other.

\section{Results and Discussion}

According to the microstructure test results, the contamination of the clay by vinyl chloride and 1, 1, 2-trichloroethane in field or contaminated by indoor soaked TCE can be clearly observed, and the interaction between the clay samples and organic pollutants can also be observed. After that, the clay samples will have an obvious flocculation phenomenon, and it can also be observed that the intergranular pores become larger and the quantity becomes more, although no obvious overhead pores are formed. Through the pore size distribution test, it can be found that the mesoporosity and macroporosity in the field contaminated clay and indoor contaminated clay by TCE are increased, and the increase of indoor contaminated clay by trichloroethylene soaked is obvious. This showed that the long-term interaction between NAPL pollutants and clay samples would change the microstructural properties of the clay samples. This may be due to the fact that the intervention of pollutants has changed the structure of the electric double layer of the clay samples, the thickness of the electric double layer has become thinner, and the clay samples have flocculated. As a result, the microstructural properties of the clay samples are changed, which was also in good agreement with the obtained cation exchange content test results.

Permeability tests of the contaminated soil after the interaction between vinyl chloride, 1, 1, 2-trichloroethane, and clay showed that the permeability of contaminated samples increases gently for both in-field or in 

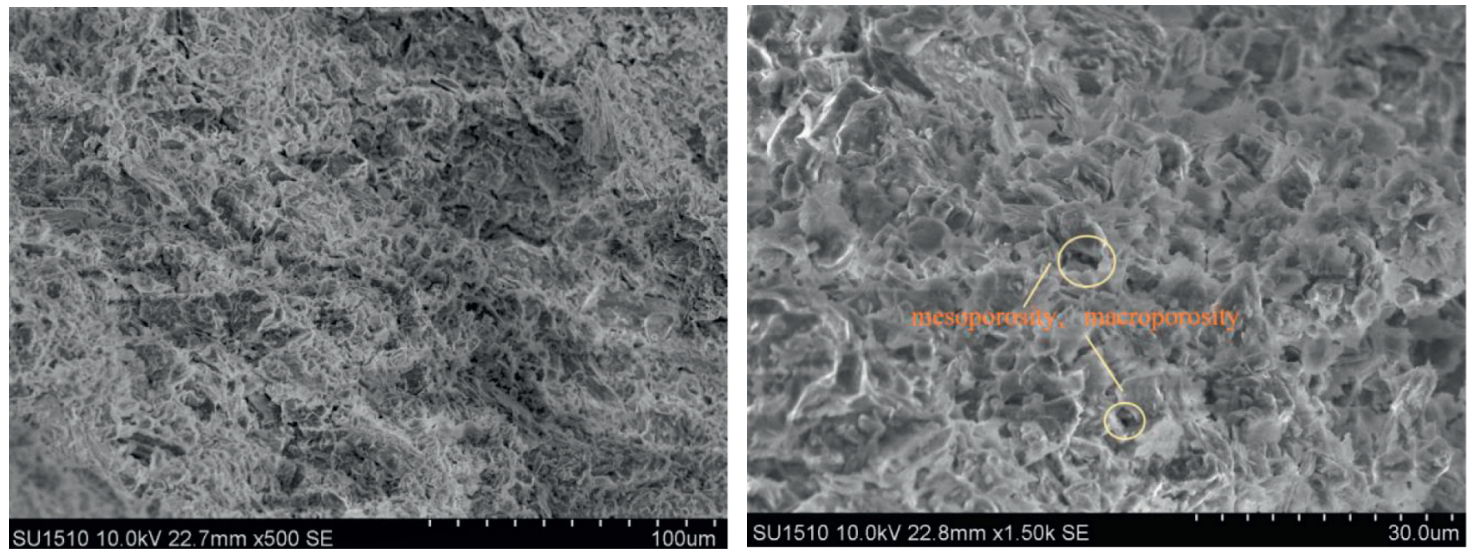

(a)
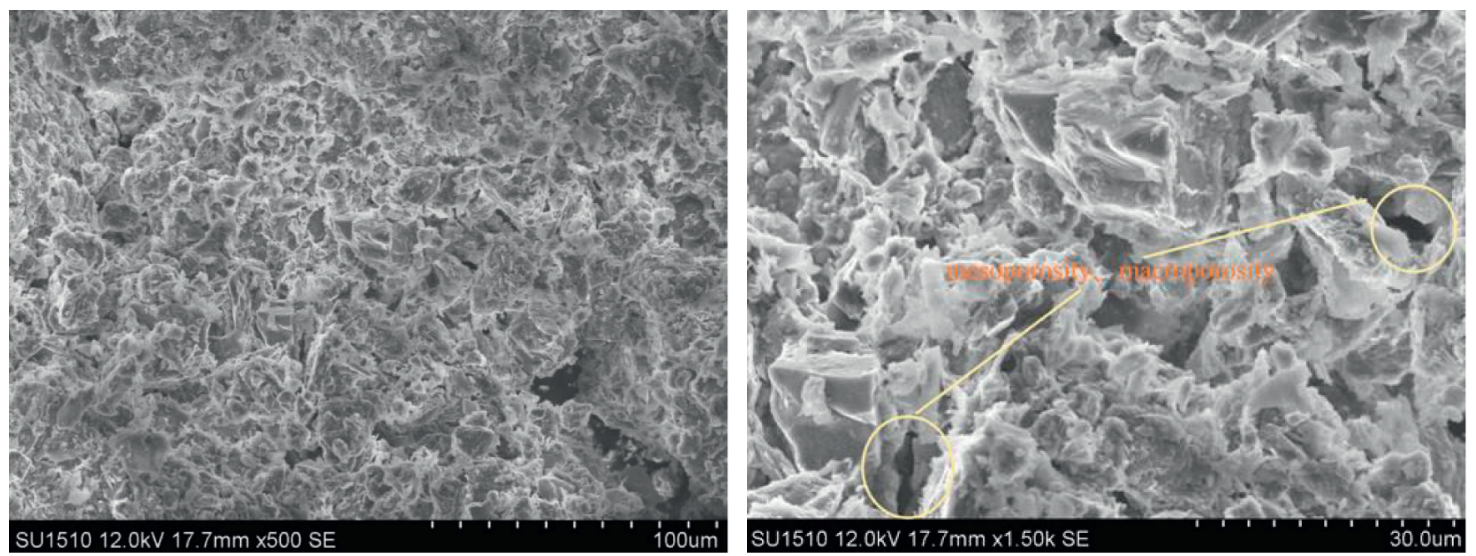

(b)
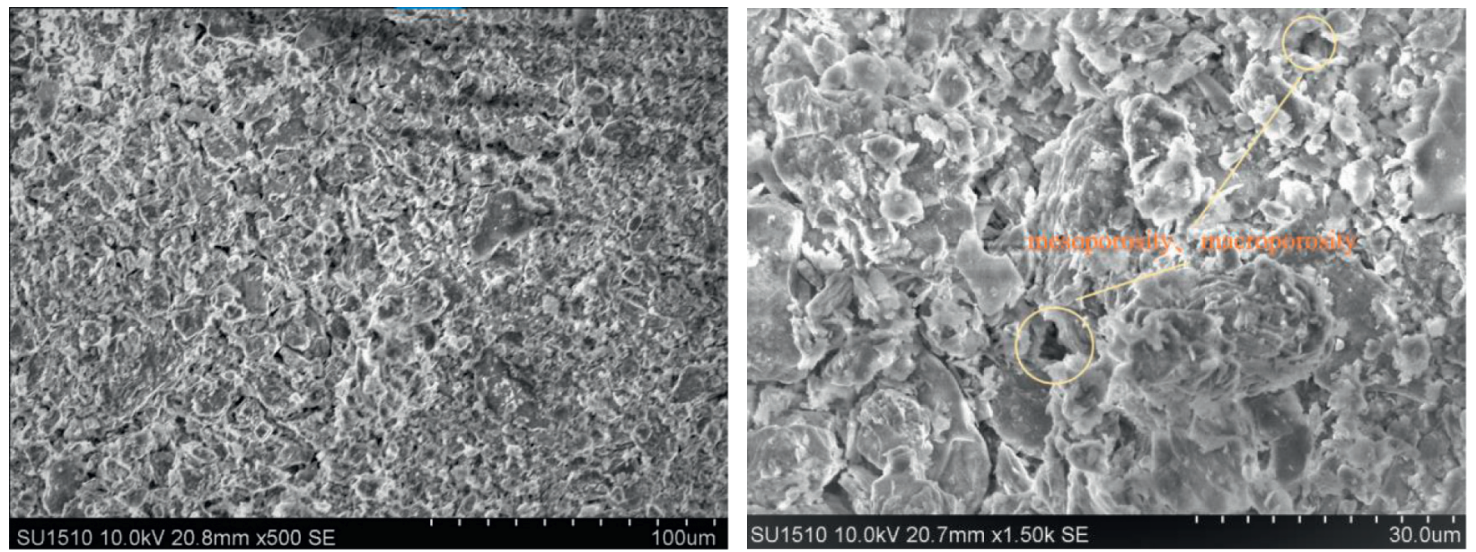

(c)

FIGURE 9: Layer (4) of the change of microstructure by SEM. (a) Uncontaminated clay. (b) The field contaminated clay. (c) Indoor soaked contaminated clay.

indoor soaked. Overall, test results showed that the insitu saturated soils yielded orders of magnitudes of the permeability coefficient $(k)$ of contaminated soils found in previous laboratory experiments. The degree of change in contaminated soil is much smaller. The main reason may be that the content of pollutants in the contaminated soil at the site is much smaller, and the content of montmorillonite, which is more active in clay minerals, is also smaller.
Table 10 shows the proportion of the distribution of macropores, mesopores, and small pores in the contaminated soil samples. It can be seen that the content of macropores, medium, and large pores in all contaminated soil samples occupies a certain proportion. The field contaminated clay samples and indoor soaked contaminated clay samples of TCE are especially obvious. Therefore, it can be preliminarily judged that such large pores were likely to be the channels for the migration of DNAPL in these 
saturated clay soils and the space for occurrence. However, it was difficult to draw a definite conclusion based on the existing information whether such a low content of DNAPL migrates in the soil in a continuous fluid manner or in the form of dispersed tiny oil droplets.

Soft clay soils in Shanghai and other areas along the southeast coast generally have a flocculation structure, so it is possible that there are ubiquitous channels for DNAPL to invade and migrate. In this way, it is difficult for these marine sedimentary saturated clay soils to block the vertical migration of DNAPL. In the absence of denser hard clay with better pore structure characteristics as a blocking layer in the deep, if such contaminated sites cannot be treated and controlled in time, the aquifers buried under these clay soils will undoubtedly be affected by DNAPL.

Based on the results of microstructure test results and permeability test results, it can be seen that the NAPL pollutants can penetrate into the clay and change the microstructure characteristics of the clay to some extent under the long-term interaction; however, the permeability coefficient is not increased by orders of magnitude. This is due to the absence of overhead pores and perforating fractures, even if flocculation and fractures occur. Therefore, under indoor trichloroethylene immersion and on-site trichloroethylene and 1,1,2-trichloroethane pollution, the permeability of contaminated clay only increases slightly. Of course, it is possible that the permeability coefficient of contaminated clay will increase more obviously as the interaction time goes on.

\section{Conclusion}

Under the interaction of vinyl chloride and 1, 1, 2-trichloroethane with clay, the plastic limit and liquid limit of the contaminated clay samples at layers (2)-(5) in Shanghai decreased slightly, the plasticity index did not change obviously, and the cation exchange capacity and mechanical properties changed obviously. The cation exchange content, porosity ratio, and permeability coefficient of the contaminated clay all showed an increasing trend, but the order of magnitude did not change. The content of volatile pollutants was not detected and no free phase was formed.

The clay would shrink and crack after indoor vinyl chloride was soaked, and the shrinkage and crack were gradually aggravated with interaction time. Compared with the field contaminated clay, the indoor contaminated clay contains more volatile vinyl chloride pollutants, but no trichloroethylene free phase was found in the contaminated clay.

It was found that even though the amount of vinyl chloride contaminant in clay was small, it was enough to cause observable changes in the microstructure of contaminated clay. The results showed that the flocculation of the contaminated clay was intensified, the macropore components increased, and the total porosity, cumulative pore volume, and average pore diameter all increased. The pore diameter between particles became larger, but no overhead pores and connected fractures were formed. This phenomenon indicated that under long-term interaction, the microstructural characteristics of the contaminated clay would have visible changed, which would have a certain impact on the migration characteristics of pollutants. Therefore, attention should be paid to the environmental engineering problem of the intrusion of vinyl chloride pollutants into the clay.

It was found that the permeability coefficient of clay increased obviously under the injection of NAPL organic pollutants. In this paper, the permeability test of clay samples with obvious shrinkage and cracking was conducted by using the improved rigid wall test device. It was found that even the indoor trichloroethylene soaked contaminated clay samples had higher volatile pollutants detected value. No order of magnitude change in the permeability coefficient was found. From the point of NAPL interaction with clay samples, the clay sample shrinkage cracking phenomenon will be more and more obvious. The microstructure of the clay sample has a certain degree of change, and the permeability coefficient has a certain degree of increase. This showed that under the long-term interaction between NAPL and saturated soft samples, the microstructure properties and permeability characteristics of saturated soft samples would change significantly.

\section{Data Availability}

The data reported in this article are available from the corresponding author upon request.

\section{Conflicts of Interest}

The authors declare no conflicts of interest, and the manuscript is approved by all authors for publication.

\section{Acknowledgments}

This study was supported by the National Natural Science Foundation of China (41772293).

\section{References}

[1] T. Liang and L. M. Hu, "Environmental geotechnics: state-ofthe-art of theory, testing and application to practice," China Civil Engineering Journal, vol. 49, no. 3, pp. 6-30, 2016.

[2] J. K. Mitchell, Fundamentals of Soil Behavior, John Wiley \& Sons, New York, NY, USA, 1976.

[3] K. W. Bromn and J. A. Thomas, "Mechanism by which organic liquids increase the hydraulic conductivity of compacted clay materials," Soil Science Society of America Journal, vol. 51, no. 6, pp. 1451-1459, 1987.

[4] J. J. Bowders, "The influence of various concentrations of organic liquids on the hydraulic conductivity of compacted clay,” Geotechnical Engineering, vol. 85, no. 2, p. 218, 1958.

[5] K. W. Brown, J. W. Green, and J. C. Thomas, "The influence of selected organic liquids on the permeability of clay liners," in Proceedings of the Ninth Annual Research Symposium on Land Disposal, Incineration, and Treatment of Hazardous Waste, pp. 114-125, Environmental Protection Agency, Cincinnati, OH, USA, May 1983.

[6] F. Fernandez and R. M. Quigley, "Hydraulic conductivity of natural clays permeated with simple liquid hydrocarbons," 
Canadian Geotechnical Journal, vol. 22, no. 2, pp. 205-214, 1985.

[7] F. T. Madsen and J. Mitchell, "Chemical effects on clay farbric and hydraulic conductivity," Land, vol. 20, pp. 201-251, 1989.

[8] T. Huckel, M. Kaczmarek, and P. Caramuscio, "Theoretical assessment of fabric and permeability changes in clays affected by organic contaminants," Canadian Geotechnical Journal, vol. 34, no. 4, pp. 588-603, 2011.

[9] J. J. Bowders and D. E. Daniel, "Hydraulic conductivity of compacted clay to dilute organic chemicals," Journal of Geotechnical Engineering, vol. 113, no. 12, pp. 1432-1448, 1987.

[10] T. Sale, C. Newell, and H. Stroo, "Frequently asked questions regarding management of chlorinated solvents in soils and groundwater," 2008.

[11] R. E. Korzeniowska and M. D. Izdebska, "Evaluation of the influence of oil pollution on particle size distribution and plasticity of clay soils," Inzynieria I Ochrona Srodowiska, vol. 9, pp. 89-103, 2006.

[12] M. Khamehchiyan, A. H. Charkhabi, and M. Tajik, "Effects of crude oil contamination on geotechnical properties of clayey and sandy soils," Engineering Geology, vol. 89, no. 3, pp. 220-229, 2007.

[13] C. R. Faust, "Transport of immiscible fluids within and below the unsaturated zone: a numerical model," Water Resources Research, vol. 21, no. 4, pp. 587-596, 1985.

[14] S. W. Chapman and B. L. Parker, "Plume persistence due to aquitard back diffusion following dense nonaqueous phase liquid source removal or isolation," Water Resources Research, vol. 41, no. 12, pp. 2179-2187, 2005.

[15] H. F. Stroo, A. Leeson, and J. A. Marqusee, P. C. Johnson, C. H. Ward, M. C. Kavanaugh et al., Chlorinated ethene source remediation: lessons learned," Environmental Science \& Technology, vol. 46, no. 12, pp. 6438-6447, 2012.

[16] K. W. Brown and J. C. Thomas, "A mechanism by which organic liquids increase the hydraulic conductivity of compacted clay materials," Soil Science Society of America Journal, vol. 51, no. 6, pp. 1451-1459, 1987.

[17] A. Kaya and H.-Y. Fang, "The effects of organic fluids on physicochemical parameters of fine-grained soils," Canadian Geotechnical Journal, vol. 37, no. 5, pp. 943-950, 2000.

[18] H. X. Shi and T. L. Huang, "Characteristics of adsorption of mineral oils on loess," Environmental Science \& Technology, vol. 25, no. 3, pp. 10-12, 2012.

[19] X. Zhou, Y. Cai, and M. G. Sun, "Experimental study on engineering properties of silty clay contaminated by diesel oil in Shanghai," Geotechnical Investigation \& Surveying, vol. 43, no. 3, pp. 1-11, 2015.

[20] O. Paykov, Influence of Organic Pore Fluid on Geotechnical Properties of Soil, California State University, Fullerton, CA, USA, 2012.

[21] D. Izdebska-Mucha, J. TrzcińSk, and M. S. Żbik, R. L. Frost, Influence of hydrocarbon contamination on clay soil microstructure," Clay Minerals, vol. 46, no. 1, pp. 47-58, 2011.

[22] J. Trzciński, D. J. Williams, and M. S. Żbik, "Can hydrocarbon contamination influence clay soil grain size composition," Applied Clay Science, vol. 109-110, pp. 49-54, 2015.

[23] D. M. Izdebska and J. Trzcinski, "Effects of petroleum pollution on clay soil microstructure," Geologija, vol. 50, pp. 68-74, 2008.

[24] D. C. Anderson, W. Crawley, and J. D. Zabcik, "Effects of various liquids on clay soil: bentonite slurry mixtures," $\mathrm{Hy}$ draulic Barriers in Soil and Rock, ASTM International, West Conshohocken, PA, USA, 1985.
[25] A. S. Abdul, T. L. Gibson, and D. N. Rai, "Laboratory studies of the flow of some organic solvents and their aqueous solutions through bentonite and kaolin clays," Ground Water, vol. 28, no. 4, pp. 524-533, 1990.

[26] G. S. Sun and D. T. Zheng, Soft Soil Foundation and Underground Engineering, China Architecture \& Building Press, Beijing, China, 1987.

[27] M. L. He, "The clay minerals and textures of shallow soil related with land surface settlement in shanghai city," Shanghai Land \& Resources, vol. 10, no. 4, pp. 31-40, 1989.

[28] Ministry of Housing and Urban-Rural Development of the People's Republic of China, Standard for Geotechnical Testing Method: GB/T 50123-2019, China Planning Press, Beijing, China, 2019.

[29] T. W. Griffin and K. W. Watson, "A comparison of field techniques for confirming dense nonaqueous phase liquids," Groundwater Monitoring \& Remediation, vol. 22, no. 2, pp. 48-59, 2002.

[30] T. T. Shen, "Laboratory research on adsorption coefficients of trichloroethylene in different soils," Contemporary Chemical Industry, vol. 9, no. 4, pp. 568-571, 2002.

[31] J. J. Bozzola, "Electron microscopy principles and techniques for biologists," Quarterly Review of Biology, vol. 2, 1999.

[32] M. Fukue, T. Minato, and H. Horibe, "The microstructure of clay given by resistivity measurements," Engineering Geology, vol. 54, no. 1-2, pp. 43-53, 1999.

[33] X. W. Zhang and L. W. Kong, "Study of pore characteristics of offshore clay by SEM and MIP and NA methods," Rock and Soil Mechanics, vol. 34, no. 2, pp. 134-142, 2013.

[34] H. L. Bian, G. J. Cai, S. Y. Liu, and G. Q. Geng, "Strength properties and microscopic mechanism of organochlorine pesticide contaminated soil," Chinese Journal of Underground Space and Engineering, vol. 10, no. 6, pp. 1317-1323, 2014.

[35] L. Y. Xu, Research for Microstructure of Hangzhou Soft Clay, Zhejiang University, Hangzhou, China, 2015.

[36] B. Shi and H. T. Jiang, "Research on the analysis the chniques for clayey soil microstructure," Chinese Journal of Rock Mechanics and Engineering, vol. 20, no. 6, pp. 864-870, 2001. 